\title{
Interaction of prion protein with acetylcholinesterase: potential pathobiological implications in prion diseases
}

Joan Torrent ${ }^{1 *}$, Alba Vilchez-Acosta ${ }^{1}$, Diego Muñoz-Torrero ${ }^{2}$, Marie Trovaslet $^{3}$, Florian Nachon ${ }^{3}$, Arnaud Chatonnet ${ }^{4}$, Katarina Grznarova ${ }^{1}$, Isabelle Acquatella-Tran Van Ba ${ }^{5,6,7}$, Ronan Le Goffic ${ }^{1}$, Laetitia Herzog ${ }^{1}$, Vincent Béringue ${ }^{1}$ and Human Rezaei ${ }^{1}$

\begin{abstract}
Introduction: The prion protein (PrP) binds to various molecular partners, but little is known about their potential impact on the pathogenesis of prion diseases

Results: Here, we show that PrP can interact in vitro with acetylcholinesterase (AChE), a key protein of the cholinergic system in neural and non-neural tissues. This heterologous association induced aggregation of monomeric PrP and modified the structural properties of PrP amyloid fibrils. Following its recruitment into PrP fibrils, AChE loses its enzymatic activity and enhances PrP-mediated cytotoxicity. Using several truncated PrP variants and specific tight-binding AChE inhibitors (AChEis), we then demonstrate that the PrP-AChE interaction requires two mutually exclusive sub-sites in PrP $\mathrm{N}$-terminal domain and an aromatic-rich region at the entrance of AChE active center gorge. We show that AChEis that target this site impair PrP-AChE complex formation and also limit the accumulation of pathological prion protein ( $\mathrm{PrP}^{\mathrm{SC}}$ ) in prion-infected cell cultures. Furthermore, reduction of AChE levels in prion-infected heterozygous AChE knock-out mice leads to slightly but significantly prolonged incubation time. Finally, we found that AChE levels were altered in prioninfected cells and tissues, suggesting that AChE might be directly associated with abnormal PrP.
\end{abstract}

Conclusion: Our results indicate that AChE deserves consideration as a new actor in expanding pathologically relevant PrP morphotypes and as a therapeutic target.

Keywords: Amyloid, Protein misfolding, Protein aggregation, Neurodegeneration

\section{Introduction}

The prion protein $(\mathrm{PrP})$ plays a key role in the pathogenesis of transmissible spongiform encephalopathies, also known as prion diseases $[1,2]$. These fatal and infectious neurodegenerative conditions are caused by prions, which consist mainly, if not exclusively, of misfolded pathological conformers $\left(\mathrm{PrP}^{\mathrm{Sc}}\right)$ of the host cellular $\operatorname{PrP}$ isoform $\left(\operatorname{PrP}^{\mathrm{C}}\right)$ [3].

While the massive contribution of PrP conformational changes to the etiology of prion diseases is widely recognized, less is known about the role of other molecules that interact directly with PrP. The large number of potential $\operatorname{PrP}^{\mathrm{C}}$-interacting molecules [4-7] suggests that $\operatorname{PrP}^{\mathrm{C}}$, which

\footnotetext{
* Correspondence: joan.torrent@inserm.fr

${ }^{1}$ Institut National de la Recherche Agronomique, UR892, Virologie

Immunologie Moléculaires, Jouy-en-Josas F-78350, France

Full list of author information is available at the end of the article
}

is preferentially localized in lipid rafts, is a key member of a multi-protein complex at the plasma membrane. Moreover, results obtained using the protein misfolding cyclic amplification procedure are consistent with an essential role of auxiliary macromolecules in PrP conformational rearrangements, leading to prion infectivity and strain maintenance [8-10]. It is therefore reasonable to hypothesize that in specific cellular environments in the nervous and lymphoreticular systems, interaction with a common molecular partner might promote the selection and enrichment of thermodynamically and conformationally unique PrP morphotypes among the plethora of structurally distinct species predicted by the high-dimensional PrP folding energy landscape [11]. These PrP morphotypes may lie at the origin of prion diseases. 
To investigate the influence of a biological factor on PrP structural changes and morphotype selection, we focused on acetylcholinesterase (AChE), a widely distributed protein in mammalian tissues and fluids with a large spectrum of functions. Like $\operatorname{PrP}^{\mathrm{C}}$, $\mathrm{AChE}$ essentially concentrates in the lipid raft fraction of the plasma membrane and is found in two different tissues where prion can be replicated: the synaptic terminals in cholinergic and non-cholinergic brain areas and reticuloendothelial cells of lymphoid organs $[12,13]$. There is compelling evidence that beyond the well-known hydrolysis of the neurotransmitter acetylcholine in cholinergic synapses, AChE exerts a variety of lesscharacterized "non-classical" roles (attributed to a nonenzymatic activity or to its cholinergic action in non-neural tissues) in stress responses and immunity, neuritogenesis and neurodegeneration [14-17]. Indeed, AChE might contribute to Alzheimer's disease $(\mathrm{AD})$ pathogenesis through its ability to interact with amyloid $\beta(A \beta)$ and to increase neuronal death [18-20], the amyloid burden and cognitive deficits in mice $[21,22]$. A $\beta$ pro-aggregating activity appears to be mediated by the peripheral anionic site (PAS) of AChE [23], located at the mouth of a $20 \AA$ deep narrow gorge, at the bottom of which is placed the catalytic site $[24,25]$. Hence, AChE inhibitors (AChEis), designed to interact with both the active and PAS sites of AChE, strongly inhibit not only AChE catalytic activity, but also AChE-induced $A \beta$ assembly [26-29]. Recent evidence indicates that AChE also mediates the assembly of two synthetic peptide fragments spanning residues $106-126$ and $82-146$ of $\operatorname{PrP}$ and that these interactions are impaired by AChEis that specifically bind to the PAS site [30,31]. Nevertheless, the influence of AChE in full-length PrP conformational changes, and its functional link to prion replication and pathogenesis remain to be determined. Here we addressed the hypothesis that a broader non-enzymatic function of $\mathrm{AChE}$ in PrP misfolding and aggregation could be relevant in prion diseases. Indeed, reduced AChE activity in lumbar CSF samples and altered AChE glycosylation in the brain and CSF samples of patients with Creutzfeldt-Jakob disease (CJD) have been observed $[32,33]$. Therefore, we investigated the role of $\mathrm{AChE}$ in prion pathogenesis, focusing both on its effect on PrP aggregation and PrP-mediated toxicity. First we found that two established AChEis hindered $\operatorname{PrP}^{\mathrm{Sc}}$ accumulation in cell cultures. Using biophysical and biochemical approaches, we then demonstrate that $\mathrm{AChE}$ binds to both monomeric and amyloid fibril conformers of full-length recombinant PrP. We show that the resulting hetero-assemblies have higher cytotoxicity. Once recruited into PrP fibrils, AChE loses its enzymatic activity. The use of different truncated $\operatorname{PrP}$ variants revealed that $\mathrm{AChE}$ directly interacts with $\operatorname{PrP}$ $\mathrm{N}$-terminal domain. Through AChEi reduction of $\mathrm{AChE}$ binding to both PrP conformers, we demonstrate that an aromatic-rich hotspot in the AChE active center gorge entrance is involved in the formation of the heterologous complex. Moreover, reduced AChE levels in prion-infected heterozygous $\mathrm{AChE}$ knockout $\left(\mathrm{AChE}^{+/-}\right)$mice led to significantly longer survival compared to wild type controls. Finally, we found that $\mathrm{AChE}$ levels were altered in brain and spleen of prion-infected mice and also in infected cell cultures compared to non-infected controls.

\section{Materials and methods}

\section{Recombinant PrP and AChE}

Full-length human PrP and different His-tagged truncated forms $(\Delta 23-99, \Delta 100-120, \Delta 23-99, \Delta 121-231$ and $\Delta 23-120)$ were produced in Escherichia coli and purified as described previously [34]. Purified monomeric PrPs were stored lyophilized and recovered in the desired buffer by elution through a G25 desalting column (GE Healthcare). Full-length human AChE was expressed in Chinese hamster ovary $(\mathrm{CHO})$ cells and purified from cell culture medium as described previously [35]. Purified dimeric AChE was concentrated using a centricon-30 ultrafiltration micro-concentrator from Amicon (Millipore Corporation, Billerica, MA, USA) and stored at $4^{\circ} \mathrm{C}$. All concentrations given for fibrillar $\operatorname{PrP}$ and dimeric $\mathrm{AChE}$ refer to the respective equivalent monomer concentration.

\section{AChEis}

Racemic huprine $\mathrm{Y}$ and Hup8TH were prepared in the form of hydrochloride salts as previously described [36,37], whereas tetrahydroaminoacridine hydrochloride (tacrine), huperzine $\mathrm{A}$ and propidium iodide were purchased from Sigma-Aldrich.

\section{Cell culture}

MovS6 cells are immortalized neuroglial cells isolated from transgenic mice that express ovine PrP [38]. Cells were grown in Opti-MEM medium with L-glutamine supplemented with $10 \%$ fetal calf serum, $1 \%$ penicillinstreptomycin. Cell cultures were infected at $80 \%$ confluence in 12-well plates with the $127 \mathrm{~S}$ strain of sheep scrapie $(50 \mathrm{ml}$ of $0.2 \%(\mathrm{w} / \mathrm{v})$ brain homogenate of terminally ill $\operatorname{tg} 338$ mice in $2 \mathrm{ml}$ of culture medium) as described in [39]. Four days after exposure, cells were carefully rinsed and passaged at a 1:10 dilution in 25$\mathrm{cm}^{2}$ flasks (passage 1). Cells were further incubated and diluted 1:10 at each following passage.

\section{$\mathrm{PrP}^{\mathrm{Sc}}$ clearance assay and immunoblotting}

Infected MovS6 cells $\left(\sim 10^{6} / 25 \mathrm{~cm}^{2}\right.$ flasks) were incubated with various $\mathrm{AChEis}$ at different final concentrations for 6 days. At confluence, cells were lysed and treated as described in [38]. Cell viability was assayed using the (3[4,5-dimethylthiazol-2-yl]-2,5- diphenyltetrazolium bromide; thiazolyl blue) MTT reduction assay (Sigma-Aldrich) according to the manufacturer's instructions. Western blotting was performed according to standard procedures. The 
SAF32 monoclonal antibody [40], an IgG against the octarepeat domain, was used to detect $\operatorname{PrP}^{\mathrm{C}}$; the Sha31 monoclonal antibody (epitope 148-159) [40] was used to detect $\mathrm{PrP}^{\text {res }}$ on immunoblots. Detection of $\mathrm{AChE}$ was done as described above using a rabbit anti- $\mathrm{AChE}$ antibody [41]. To confirm equal protein loading, membranes were also probed with the anti-b-actin antibody clone AC-74 (Sigma-Aldrich). Band intensity for $\operatorname{PrP}^{\mathrm{Sc}}$ was measured using the GeneTools software after acquisition of chemiluminescent signals with a GeneGnome digital imager (Syngene).

\section{Formation of amyloid fibrils}

PrP amyloid fibrils were formed using the manual setup protocol described previously by [42]. Fibril formation was monitored using a ThT binding assay [42]. Samples were dialyzed in $10 \mathrm{mM}$ sodium acetate, $\mathrm{pH}$ 5.0. Then fibrils were collected by ultracentrifugation and resuspended in $10 \mathrm{mM}$ sodium acetate, $\mathrm{pH}$ 5.0. A washing step was performed by repeating the ultracentrifugation and resuspension steps.

\section{Transmission Electron Microscopy (TEM)}

Samples were deposited on Formvar carbon-coated grids, negatively stained with freshly filtered $2 \%$ uranyl acetate, dried and viewed using a JEOL 1200EX2 electron microscope (JEOL USA, Inc, Peabody, USA). For immunogold labeling, samples adsorbed onto grids and air-dried were washed with $\mathrm{H}_{2} \mathrm{O}$. Non-specific binding was blocked by incubation in PBS with $1 \%(\mathrm{w} / \mathrm{v})$ bovine serum albumin (BSA) for $15 \mathrm{~min}$. Grids were then placed onto a droplet of H-134 anti-AChE polyclonal antibody (Santa Cruz Biotechnology, Inc. Heidelberg, Germany) diluted $1 / 25$ in PBS with $1 \%(\mathrm{w} / \mathrm{v})$ BSA for $1 \mathrm{~h}$. Grids were then washed in three droplets of PBS with $1 \%(\mathrm{w} / \mathrm{v})$ BSA (4 min/each) and placed on a droplet of anti-rabbit IgG conjugated to $10 \mathrm{~nm}$ colloidal gold particles for $45 \mathrm{~min}$ (Sigma-Aldrich) diluted $1 / 50$ in PBS with $0.1 \%(\mathrm{w} / \mathrm{v})$ BSA. Before viewing, grids were washed with $\mathrm{H}_{2} \mathrm{O}$ and negatively stained with freshly filtered $2 \%$ uranyl acetate.

\section{Fluorescence measurements}

Fluorescence measurements were performed at $20^{\circ} \mathrm{C}$ using a FP-6200 fluorimeter (Jasco France, Bouguenais, France). Aliquots of each protein sample were incubated with $10 \mu \mathrm{M}$ thioflavin $\mathrm{T}$ (ThT) for $1 \mathrm{~min}$ or $50 \mu \mathrm{M}$ 8-anilino-1-naphthalene sulfonate (ANS) at room temperature for $10 \mathrm{~min}$ before fluorescence measurements. For ANS spectra, excitation was at $385 \mathrm{~nm}$. ThT emission spectra were recorded after excitation at $450 \mathrm{~nm}$. The excitation and emission slit widths were $4 \mathrm{~nm}$.

\section{Static light scattering (SLS)}

Static light scattering kinetic experiments were performed with a homemade device using a 407-nm laser beam. Lightscattered signals were recorded at a $112^{\circ}$ angle. Signals were processed with a homemade MatLab program. This technique was coupled with size-exclusion chromatography, to estimate the absolute molecular weight of $\mathrm{AChE}$ (oligomeric state) using the relationship between the intensity of light scattered by the molecule and its molecular weight and concentration, as described by the Rayleigh theory. A $60 \times$ $0.78 \mathrm{~cm}$ TSK4000SW column (Tosoh Bioscience, Worcestershire, UK) was used with $20 \mathrm{mM}$ Mes $\mathrm{pH} 6.0$ as elution buffer. The temperature of the column was maintained at $18^{\circ} \mathrm{C}$. Carbonic anhydrase was used as standard protein for calibration purposes.

\section{Differential scanning calorimetry (DSC)}

Differential scanning calorimetry experiments were performed using a VP-DSC MicroCalorimeter device (GE Healthcare) with a temperature scan rate of $1^{\circ} \mathrm{C} / \mathrm{min}$. Thermograms were recorded using $50 \mu \mathrm{M} \operatorname{PrP}$ in the presence or not of $50 \mu \mathrm{M}$ Hup8TH. To ensure reversible thermal denaturation conditions, $10 \mathrm{mM}$ sodium citrate $\mathrm{pH} 4.6$ was used.

\section{$\mathrm{BS}^{3}$ cross-linking experiments}

Cross-linking was induced at $25^{\circ} \mathrm{C}$ by the addition of $\mathrm{BS}^{3}$ (500 $\mu \mathrm{M}$ final concentration) (Thermo Fisher Scientific, Rockford, IL, USA) in a solution of $10 \mu \mathrm{M}$ PrP, $5 \mu \mathrm{M}$ AChE or a mix of both proteins in $20 \mathrm{mM}$ Hepes, $\mathrm{pH}$ 7.0. Reactions were stopped after $10 \mathrm{~min}$ by adding an excess of amine groups with $50 \mathrm{mM}$ Tris- $\mathrm{HCl}$ buffer. After addition of Laemmli buffer, samples were heated at $100^{\circ} \mathrm{C}$ for 10 min and separated by SDS-PAGE on $12 \%$ Criterion $^{\text {Tw }}$ XT Bis-Tris Precast Gels (Bio-Rad) followed by silver staining.

\section{Fibril annealing and PK digestion assay}

PrP fibrils in the presence or absence of AChE were treated as described previously [43]. Samples were heated in denaturing sample buffer $(60 \mathrm{mM}$ Tris- $\mathrm{HCl}, 2 \%$ SDS, $5 \% \beta$-mercaptoethanol, $2.25 \mathrm{M}$ urea) at $95^{\circ} \mathrm{C}$ for $15 \mathrm{~min}$ and separated on $12 \%$ Criterion $^{\mathrm{Tm}}$ XT Bis-Tris Precast Gels (Bio-Rad) followed by silver staining. Quantification of protein-band intensities was performed by densitometric analysis using NIH ImageJ software (National Institutes of Health, Bethesda, MD).

\section{Primary neuronal cells}

Primary cell cultures of neurons were derived from the cerebral cortex of 17.5 E mouse embryos and carried out as reported previously [44]. $20 \mu \mathrm{M}$ of recombinant $\operatorname{PrP}$ isoforms (soluble, fibrils) were pre-incubated in $10 \mu \mathrm{M}$ $\mathrm{AChE}$ at $37^{\circ} \mathrm{C}$ for 30 minutes before their addition to the cells at a final concentration of 1 and $0.5 \mu \mathrm{M}$, respectively. After 72 hours in vitro, the cytotoxic effect of each treatment was analyzed by fixing cells in $4 \%$ paraformaldehyde solution and staining with Hoechst 33258. Apoptotic cells were identified by the characteristic 
nuclear bright blue fluorescence due to condensed or fragmented chromatin. Neurons were identified with a primary mouse anti-beta 3 tubulin antibody (1:400; Sigma-Aldrich) and revealed by staining with an anti-mouse $\mathrm{Cy} 3$ secondary antibody (1:400; Jackson ImmunoResearch Europe Ltd., Suffolk, UK). Digital images were captured from 10 random fields for each sample $(\approx 3500$ cells total) using an Axiovert 200 M Zeiss inverted microscope (Carl Zeiss S.A.S., Marly le Roi, France). Neuronal cell death was determined by counting the bright neurons and expressed as the percentage of the total cell number compared with control cultures. Data were analyzed by one-way analysis of variance and a Tukey test was carried out on the results of four independent experiments.

\section{Inhibition of AChE enzymatic activity}

7.3 nM AChE was mixed with PrP fibrils (concentration ranging from 8 to $25 \mu \mathrm{M}$ ) or $25 \mu \mathrm{M}$ monomeric $\mathrm{PrP}$ at $37^{\circ} \mathrm{C}$ in $100 \mathrm{mM}$ sodium phosphate buffer $\mathrm{pH}$ 7.4 containing $0.33 \mathrm{mg} / \mathrm{mL}$ BSA. The residual activity contained in a $10-\mu \mathrm{L}$ aliquot was monitored at $25^{\circ} \mathrm{C}$ and $\mathrm{pH} 7.4$, according to the Ellman's method, using $1 \mathrm{mM}$ acetylthiocholine and $0.5 \mathrm{mM}$ dithiobisnitrobenzoic acid and a final volume of $200 \mu \mathrm{l}$.

\section{Ethics statement}

Animal experiments were carried out in strict accordance with the EU directive 2010/63 and were approved by the authors' institution local ethics committee (Comethea; permit number 12/034).

\section{Infection of tg338 mice with LA21K fast prions}

The cloned ovine prion strain LA21K fast used in this study has been previously described [45]. Individually identified 6 to 10 week/old tg338 mice were inoculated intracerebrally with $20 \mu \mathrm{l}$ of $10 \%(\mathrm{w} / \mathrm{v})$ infected brain homogenates (prepared in $5 \%$ glucose) ( $\mathrm{n}=5$ mice). Age-matched control tg338 mice received uninfected brain homogenates $(n=5$ mice). Mice showing prion-specific neurological signs were monitored daily and euthanized at the terminal stage of prion disease. At this time point, control mice were also euthanized. After perfusion with physiological saline and euthanasia, half-brain specimens were dissected into two parts: a cortex-enriched fraction and a fraction containing the remaining brain areas. These samples were flash frozen, and stored at $-80^{\circ} \mathrm{C}$. Spleens were also rapidly removed, flash frozen, and stored at $-80^{\circ} \mathrm{C}$.

Infection of $\mathrm{AChE}^{+/-}$and $\mathrm{AChE}^{+/+}$mice with $139 \mathrm{~A}$ prions $\mathrm{AChE}^{+/-}$mice (Xie et al. 2000) and wild type $\left(\mathrm{AChE}^{+/+}\right)$littermates were maintained by breeding heterozygous males and females (129/Sv genetic background). Individually identified, 6 week/old mice were infected by intracerebral inoculation with $20 \mu \mathrm{l}$ of a $0.1 \%(\mathrm{w} / \mathrm{v}) 139 \mathrm{~A}$ mouse scrapie strain, as described above.

\section{Tissue homogenization}

Brain and spleen tissues $(10 \%(\mathrm{w} / \mathrm{v})$ and $5 \%(\mathrm{w} / \mathrm{v})$, respectively) were homogenized using a Rybolyser Precellys (Bertin Technologies, Montigny-le-Bretonneux, France) and icecold extraction buffer $(25 \mathrm{mM}$ Tris- $\mathrm{HCl}, 150 \mathrm{mM} \mathrm{NaCl}$, $\mathrm{pH}$ 7.3) containing $1 \%$ Triton X-100 and protease inhibitors (10 mM EDTA, $40 \mu \mathrm{g} / \mathrm{ml}$ leupeptin, $10 \mu \mathrm{g} / \mathrm{ml}$ pepstatin and $2 \mathrm{mM}$ benzamidine). Extracts were incubated on ice for $1 \mathrm{~h}$ and then centrifuged at $30,000 \times g$ for $30 \mathrm{~min}$. The protein content of supernatants was determined using the Bicinchoninic acid assay reagent kit (Pierce Biotechnology, Rockford, USA).

\section{Detection of $\mathrm{PrP}^{\mathrm{Sc}}$ in brain and spleen}

Before the centrifugation step of the homogenization procedure, $\mathrm{PrP}^{\mathrm{Sc}}$ was extracted with the BioRad TsSeE purification and detection kit (Marnes-la-Coquette, France) and digested with $200 \mu \mathrm{g} / \mathrm{ml}$ proteinase K (Euromedex, Mundolsheim, France) at $37^{\circ} \mathrm{C}$ for $10 \mathrm{~min}$. After denaturation in Laemmli buffer at $100^{\circ} \mathrm{C}$ for $5 \mathrm{~min}$, samples were run on $12 \%$ Criterion $^{\text {Tw }}$ XT Bis-Tris Precast Gels (Bio-Rad), electrotransferred to nitrocellulose membranes, and probed with the biotinylated anti-PrP monoclonal antibody Sha31, as previously described [46]. Immunoreactivity was visualized by chemiluminescence (GE Healthcare, Orsay, France).

\section{AChE detection in brain and spleen}

$200 \mathrm{mg}$ of total proteins were separated on $7.5 \%$ Criterion $^{\mathrm{Tm}} \mathrm{TGX}^{\mathrm{Tm}}$ Gels (Bio-Rad) in reducing conditions, and then transferred to nitrocellulose membranes. Blots were blocked in Tris-buffered saline (TBS) with $0.5 \%$ Tween 20 (TBS-T) containing $5 \%$ nonfat dried milk at $4^{\circ} \mathrm{C}$ overnight before incubation with a rabbit anti-AChE antibody [41], (1:2000 in the same TBS-T buffer) at $4{ }^{\circ} \mathrm{C}$ overnight. Blots were then incubated with peroxidaseconjugated anti-rabbit IgG antibodies (1:10,000; Abliance SAS, Compiègne, France) at room temperature for $30 \mathrm{~min}$, washed extensively and exposed to the chemiluminescent substrate ECL Plus (GE Healthcare). The amount of AChE present in each tissue was determined with the GeneTools software after acquisition of the chemiluminescent signals with a GeneGnome digital imager (Syngene, Frederick, Maryland, USA). To confirm equal protein loading, membranes were also probed with an anti- $\beta$-actin (clone AC-74; Sigma-Aldrich, SaintQuentin Fallavier, France), or anti-GAPDH antibody (Chemicon International, Temecula, USA). AChE protein values were normalized by the corresponding $\beta$ actin and GAPDH protein content. 


\section{Determination of AChE activity in brain and spleen}

Total AChE activity in the homogenates was assayed using $1 \mathrm{mM}$ acetylthiocholine and $0.5 \mathrm{mM} \mathrm{5,5-dithiobis}$ (2-nitrobenzoic acid) (DTNB) in the presence of $50 \mu \mathrm{m}$ tetra(monoisopropyl)pyrophosphortetramide (iso-OMPA) (Sigma-Aldrich). Extracts were first incubated in the absence of acetylthiocholine for at least 20 min to block butyrylcholinesterase and saturate the free sulfhydryl groups that interact with DTNB. Changes in optical density were measured at $414 \mathrm{~nm}$.

\section{RNA extraction and RT-qPCR}

Total RNAs were extracted from spleen and brain samples after homogenization in RLT buffer (RNeasy kit, Qiagen) and QIAzol Lysis Reagent (Qiagen), respectively, following the manufacturer's recommendations. Reverse-transcriptions were performed using the Superscript reverse transcriptase (Invitrogen) and random hexamers (Fermentas). The levels of choline acetyltransferase (ChAT) transcripts and of alternatively spliced AChE transcripts were measured using the Mastercycler realplex sequence detector (Eppendorf) and the double stranded DNA-specific dye SYBR Green system (Applied Biosystems) with the following primers: AChE (exon2) sense 5' -GCATACACCTTCCCTGGCTT-3', antisense 5' AAAAGCTGAGACTGGGCCTC-3'; AChE-E sense 5' TCAGCGCCACCGCCACGGAG-3', antisense 5'-AGAG GAGGGACAGGGCTAAG-3'; AChE-S sense 5' -TGTGA GCCTGAACCTGAAGC-3', antisense 5' -CTGGTTCTTC CAGTGCACCA-3'; AChE-R sense 5'-TCAGCGCCACC GGTAGGCGC, antisense 5'-AGAGGAGGGACAGGGCTAAG-3'; ChAT sense 5' -AAATGGCGTCCAACGAGGA T-3', antisense 5' -GCTCGATCATGTCCAGGGAG-3'; H PRT sense 5'-GGTTAAGCAGTACAGCCCCA-3', antisense 5' -TCCAACACTTCGAGAGGTCC-3'. PCR conditions and cycles were as follows: initial DNA denaturation at $95^{\circ} \mathrm{C}$ for $10 \mathrm{~min}$, followed by 40 cycles at $95^{\circ} \mathrm{C}$ for $15 \mathrm{sec}$, then an annealing step at $60^{\circ} \mathrm{C}$ for $15 \mathrm{sec}$, and finally an extension step at $72^{\circ} \mathrm{C}$ for $30 \mathrm{sec}$. To ensure that the primers produced a single and specific PCR amplification product, a dissociation curve was performed at the end of each PCR assay. Relative quantification was performed by using the comparative $\Delta \Delta \mathrm{Ct}$ method. The mean $\Delta \mathrm{Ct}$ obtained using samples from mock-infected mice for each isoform was used as calibrator after normalization to the endogenous control hypoxanthine-guanine phosphoribosyltransferase (HPRT). Results are presented as $\mathrm{n}$-fold difference relative to the calibrator $\left(\mathrm{RQ}=2^{-\Delta \Delta \mathrm{Ct}}\right)$.

\section{Results}

The potent tight-binding AChEis huprine $\mathrm{Y}$ and Hup8TH limit $\mathrm{PrP}^{\mathrm{Sc}}$ accumulation in prion-infected cell cultures First we asked whether AChE actively participates in $\mathrm{PrP}^{\mathrm{Sc}}$ accumulation. We thus investigated the effect of AChE inhibition in prion-infected MovS6 cells [38], a model previously used in proof of principle studies on candidate antiprion agents $[47,48]$. We chose the high-affinity reversible AChEis huprine Y (a huperzine A-tacrine hybrid) [36,49] and Hup8TH (a huprine-tacrine heterodimer) [37], based on their extremely potent inhibition of AChE catalytic activity and particularly their ability to impair AChE-induced aggregation of $\mathrm{A} \beta$ and $\operatorname{PrP}$ peptides [30,31]. In parallel, we also tested the parent compounds tacrine and huperzine A, as well as propidium iodide, a specific AChE PAS inhibitor.

Western blot analysis after PK digestion of crude extracts from confluent, prion-infected MovS6 cells cultured in the presence of $20 \mu \mathrm{M}$ of each AChEi or vehicle alone for 6 days showed that only huprine $\mathrm{Y}$ inhibited $\mathrm{PrP}^{\mathrm{Sc}}$ accumulation (Figure 1a). As Hup8TH was cytotoxic at this concentration, we repeated the experiment with non-cytotoxic doses (0.1 to $0.5 \mu \mathrm{M})$. Hup8TH treatment reproducibly led to $\mathrm{PrP}^{\mathrm{Sc}}$ level reduction and this effect was dose-dependent (Figure 1b). These results reveal that $\mathrm{AChEis}$ limit $\operatorname{PrP}^{\mathrm{Sc}}$ accumulation in an AChE-binding depending manner, i.e. tacrine (no effect) $<$ huprine $\mathrm{Y}<\mathrm{Hup8TH}$. For Hup8TH, fitting of the dose-response curve (Figure 1c) yielded a 50\% inhibitory concentration ( $\mathrm{IC}_{50}$ value) of approximately $0.22 \pm 0.01 \mu \mathrm{M}$. The toxicity of Hup8TH was assessed using the MTT metabolic assay (Figure 1c). Cell viability decreased by approximately $10 \%$ at concentrations of Hup8TH required for maximal inhibition of $\mathrm{PrP}^{\mathrm{Sc}}$ accumulation. In uninfected MovS6 cells, $\mathrm{PrP}^{\mathrm{C}}$ expression levels were unaffected by $0.5 \mu \mathrm{M}$ Hup8TH (Figure 1d), ruling out the possibility that $\mathrm{Hup} 8 \mathrm{TH}$ inhibition of $\operatorname{PrP}^{\mathrm{Sc}}$ accumulation in infected culture was due to an altered steady state level of $\operatorname{PrP}^{\mathrm{C}}$.

\section{AChE binds to PrP monomers and induces their aggregation}

To determine whether a direct $\mathrm{AChE} / \mathrm{PrP}$ interaction could explain these results, we performed SLS measurements of full length PrP mixed with increasing AChE concentrations (Figure 2a). The raise in scattering intensity upon mixing the two proteins (time zero) indicated an increase in the average molecular weight of the sample, suggesting the formation of AChE:PrP complexes. After strengthening the ionic character of the buffer by adding $200 \mathrm{mM} \mathrm{NaCl}$, the reaction was readily detected even at the molar ratio of $1.25: 100$ (AChE:PrP), confirming the interaction specificity (Figure 2b). TEM also supported AChE positive effect on PrP aggregation by showing that larger PrP assemblies were formed in the presence of AChE than in its absence (Figure 2c).

To assess whether the aggregates (identified by SLS) resulting from the interaction between $\mathrm{PrP}$ and $\mathrm{AChE}$ contained both proteins, we fractionated the solutions into supernatant $(\mathrm{S})$ and pellet $(\mathrm{P})$ fractions by ultracentrifugation and separated them by SDS-PAGE (Figure 2d). PrP 


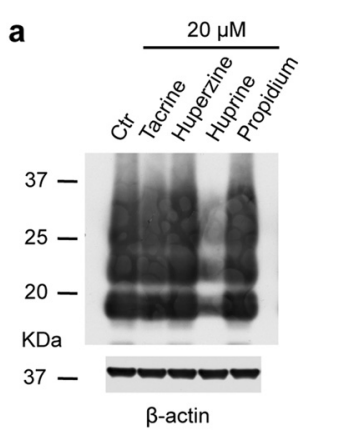

C

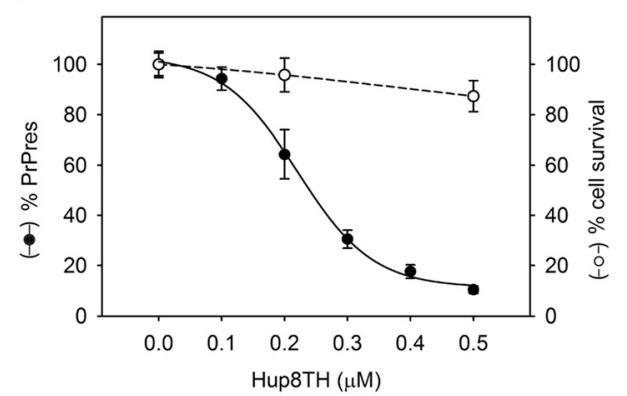

b

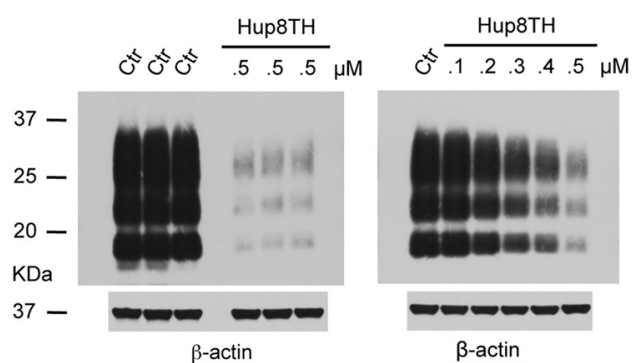

d

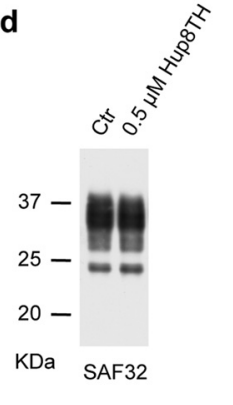

Figure 1 The tight-binding AChEis huprine $Y$ and Hup8TH efficiently decrease PrP ${ }^{S c}$ accumulation in Scrapie-infected MovS6 cells. a Scrapie-infected MovS6 cells were incubated with $20 \mu \mathrm{M}$ of the indicated AChEis for 6 days and then lysed. PrP ${ }^{S c}$ accumulation was determined by using the anti-PrP antibody Sha31b; the anti- $\beta$-actin antibody was used to control protein loading. Ctr, vehicle-treated cells. b Prion-infected MovS6 cells were incubated with $0.5 \mu \mathrm{M}$ Hup8TH or 0.1 to $0.5 \mu \mathrm{M}$ Hup8TH and then processed as in a. c Densitometric measurement of PrPSc signal, expressed as percentage relative to the untreated control (closed circles). Results are expressed as the mean \pm SD of three different experiments. Cell viability determined by using the MTT assay is also shown (open circles). The absorbance values are expressed as the mean \pm SD of four independent experiments relative to the absorbance values of the untreated control. Solid and dashed lines are fits to the data. d Protein lysates from uninfected Movs6 cells were analyzed by immunoblotting without proteinase K digestion. The effect of Hup8TH on PrPC accumulation was determined using the SAF32 antibody. Molecular weights (in kilodaltons) are indicated on the left of the blots.

and AChE alone were completely soluble, whereas, after mixing, $10-20 \%$ of the total content was present in the pellet.

To further substantiate AChE-PrP interaction, we then performed chemical crosslinking using the amineto-amine cross-linker $\mathrm{BS}^{3}$ followed by SDS-PAGE (Figure 2e). After crosslinking, $\operatorname{PrP}$ and $\mathrm{AChE}$ alone showed a unique band that corresponded to the monomeric protein. Conversely, in the mix, an additional band was visible and its molecular weight was consistent with the assembly of one PrP monomer with one AChE monomer.

To characterize the specific regions within the PrP molecule that are crucial for AChE binding, we generated various PrP truncated variants (Figure 2f). In the absence of the largely unstructured $\mathrm{N}$-terminal region of $\operatorname{PrP}$ (residues 23-120), AChE-mediated aggregate formation was abrogated. All other PrP variants allowed aggregation, albeit with varying efficacy. These results led us to conclude that AChE directly interacts with PrP unstructured $\mathrm{N}$-terminus and more precisely with two mutually exclusive sub-sites that are included between residues 23 and 99 and residues 100 and 120 .

\section{Hup8TH reduces AChE-induced aggregation of PrP}

We then assessed whether Hup8TH, the most potent anti-PrP ${ }^{\mathrm{Sc}} \mathrm{AChEi}$ in cell culture, could interfere with AChE-PrP interaction, and consequently reveal the existence of a hot spot in AChE for the binding interface. To this aim, we pre-incubated AChE with Hup8TH at molar ratios up to 1:25 (AChE:Hup8TH) at room temperature for $30 \mathrm{~min}$ and then added the solution to monomeric $\operatorname{PrP}$ (time zero). SLS measurements (Figure $2 \mathrm{~g}$ ) indicated that Hup8TH inhibited the aggregation by approximately $50 \%$ at the highest dose tested. The compound had no effect on the monitored light scattering of PrP and AChE alone. In addition, to test whether the inhibitory activity of Hup8TH relied on an unexpected direct interaction with PrP, we measured the heat-induced PrP equilibrium unfolding by DSC. To this purpose, we used $\mathrm{PrP}$ at $\mathrm{pH}$ 4.6, which allows studying the reaction as a reversible two-step process [50]. DSC thermograms of PrP in the absence and in the presence of Hup8TH at equimolar concentration showed no difference in the single endothermic peak typical of protein denaturation (Additional file 1), indicating that Hup8TH does not directly interact with PrP. 

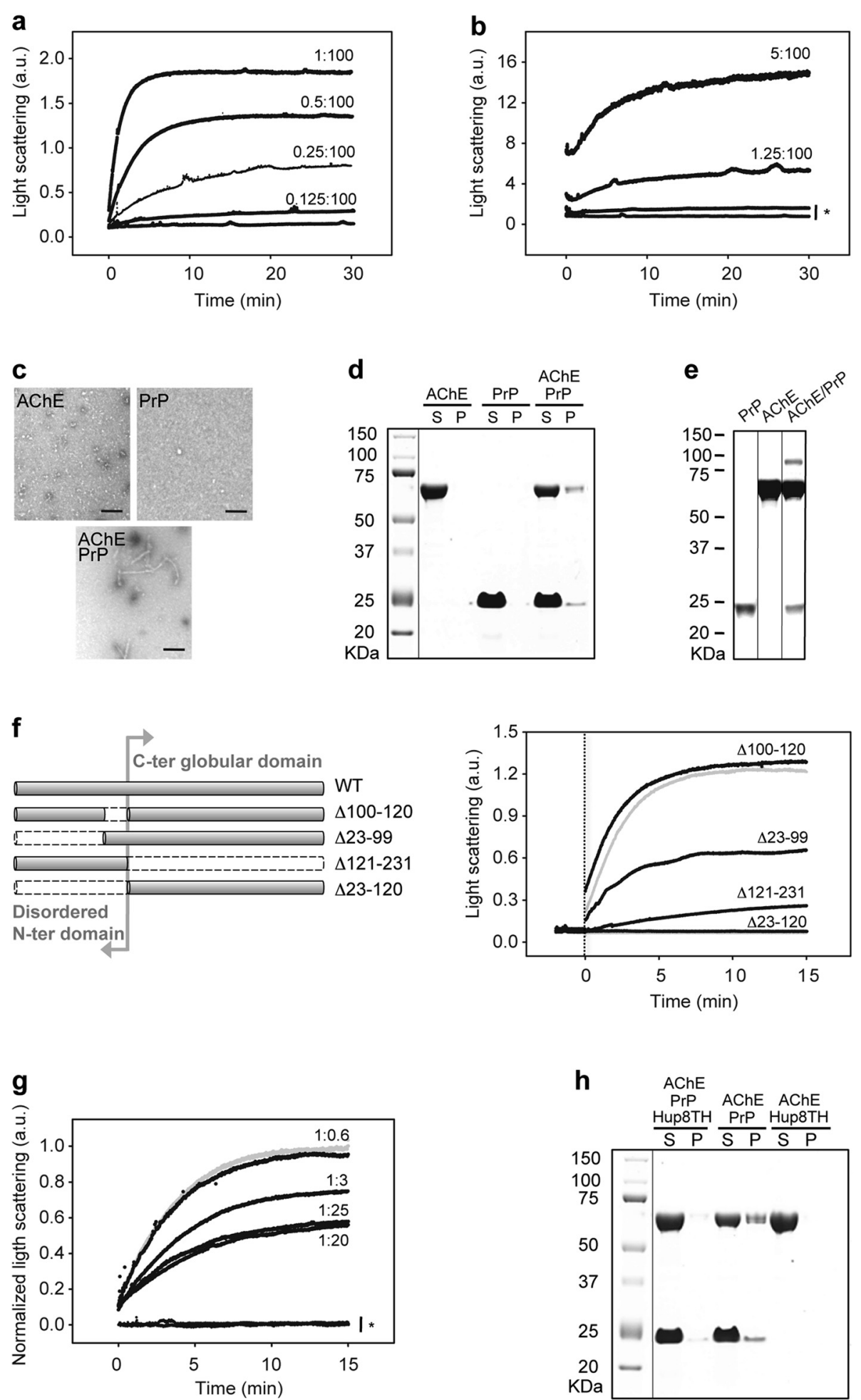

Figure 2 (See legend on next page.) 


\section{(See figure on previous page.)}

Figure 2 The formation of an aggregation-prone complex via specific interaction of AChE with PrP N-terminal domain is partially inhibited by Hup8TH. a Kinetics of AChE-PrP assembly. Increasing concentrations of AChE were added to $5 \mu \mathrm{M}$ PrP. AChE:PrP molar ratios are indicated next to the trace. The extent of protein aggregation was recorded by light scattering intensity (also in panels $\mathbf{b}, \mathbf{f}$ and $\mathbf{g}$ ). The results for AChE in the absence of PrP are not shown because they overlap with the kinetic profile of PrP alone. $\mathbf{b}$ Probing the specificity of the interaction by strengthening the ionic character of the buffer. AChE was added to $20 \mu \mathrm{M}$ PrP in the presence of $200 \mathrm{mM} \mathrm{NaCl}$. The AChE:PrP molar ratios are indicated next to the trace. The asterisk shows the kinetic profiles of AChE (lower curve) and PrP (higher curve) alone. c Negative-stained transmission electron micrographs of AChE (upper left panel), PrP (upper right panel) and a mix of both proteins (lower panel). The molar ratio used was 0.5:1 (AChE:PrP). Scale bar $=250 \mathrm{~nm}$. d The presence of both PrP and AChE in the insoluble fraction (pellet, P) after centrifugation of a mixture of $10 \mu \mathrm{M}$ PrP with $5 \mu \mathrm{M}$ AChE (incubated at $37^{\circ} \mathrm{C}$ for $30 \mathrm{~min}$ ) confirms the formation of PrP-AChE aggregates. Gels were stained with Coomassie Blue. S, soluble fraction. e BS ${ }^{3} \mathrm{cross}^{-l i n k i n g}$ assay demonstrates the formation of a heterodimer. Silver-stained gel showing $\operatorname{PrP}(10 \mu \mathrm{M})$, AChE $(5 \mu \mathrm{M})$, and a mix of both proteins after incubation with $500 \mu \mathrm{M} \mathrm{BS}^{3}$. $\mathbf{f}$ Importance of the PrP N-terminus for the heterologous interaction. Left panel: schematic representation of the various PrP constructs. Right panel: kinetics of AChE assembly with truncated PrP variants. $50 \mathrm{nM}$ AChE was added to $2 \mu \mathrm{M}$ PrP variants (the full-length PrP profile is shown as grey line). The vertical dotted line indicates when AChE was added (time zero). $\mathbf{g}$ Hup8TH decreases AChE binding to PrP. AChE was pre-incubated at room temperature with increasing concentrations of Hup8TH for 30 min (AChE:Hup8TH molar ratios from 1:0.6 to 1:25). Then, 250 nM PrP was

incubated with $50 \mathrm{nM}$ pre-treated or not (grey line) AChE (AChE:Hup8TH molar ratios are indicated next to the trace). The asterisk highlights the kinetic profiles of AChE and PrP alone incubated with the highest Hup8TH concentration. $\mathbf{h}$ The effect of Hup8TH on AChE-PrP co-aggregation was monitored by Coomassie blue staining after SDS-PAGE. $10 \mu \mathrm{M}$ PrP and $5 \mu \mathrm{M}$ AChE were incubated or not at $37^{\circ} \mathrm{C}$ with Hup8TH (1:100 molar ratio, AChE:Hup8TH) for $30 \mathrm{~min}$. Supernatant and pelleted fractions obtained after centrifugation were analyzed. Experiments were performed in $20 \mathrm{mM} \mathrm{Mes} \mathrm{buffer} \mathrm{(pH} \mathrm{6.0)}$ at $37^{\circ} \mathrm{C}$; a.u., arbitrary units. Molecular weights (in kilodaltons) are indicated to the left of the blots.

To further characterize the inhibitory effect of Hup8TH on AChE-PrP aggregation, we separated samples into pellet and supernatant fractions by ultracentrifugation. SDSPAGE analysis (Figure $2 \mathrm{~h}$ ) showed that pre-treatment of AChE with Hup8TH practically suppressed the aggregation effect. Moreover, binding of Hup8TH to AChE did not alter the enzyme solubility, excluding any decrease in the soluble AChE pool available for interaction with PrP.

These results validate the specificity of the AChE-PrP hetero-assembly and provide strong evidence for the existence of a hotspot on AChE for PrP binding that can be targeted successfully by a small inhibitor molecule.

\section{AChE associates with PrP fibrils}

We then studied whether PrP fibril structure could be modulated by AChE. The enzyme did not affect the fibrilformation process promoted by partially-denaturing solvent conditions (2 $\mathrm{M}$ guanidine- $\mathrm{HCl})$. Nevertheless, fibrils formed from a mix of $\mathrm{AChE}$ and $\operatorname{PrP}(0.5: 1$ ratio) (Figure 3a, right panel) were decorated by punctuate material, probably the co-assembled $\mathrm{AChE}$, when compared to fibrils obtained from $\mathrm{PrP}$ alone (Figure 3a, left panel).

To confirm the presence of AChE in PrP fibrils, we used immuno-electron microscopy and an anti-AChE antibody that was revealed with a secondary antibody conjugated to 10-nm gold nanoparticles (Figure 3b). Only in fibrils formed in the presence of $\mathrm{AChE}$, electron-dense gold nanoparticles colocalized with PrP fibrils (Figure $3 \mathrm{~b}$ right panel), demonstrating the interaction of $\mathrm{AChE}$ with the fibrils. The AChE-PrP assembly obtained in mild denaturing conditions highlights the specificity of the reaction.

Next, to assess whether AChE could bind also to mature pre-formed $\operatorname{PrP}$ fibrils, we incubated AChE with preformed PrP fibrils at $37^{\circ} \mathrm{C}$ for $30 \mathrm{~min}$. After centrifugation, AChE co-sedimented with PrP fibrils (Figure 4a).
Analysis by TEM of the macrostructure of this AChE: PrP fibril complex revealed thicker fibrils, compared to PrP fibrils alone, suggesting that AChE homogenously coats the filaments (Additional file 2).

We then evaluated whether $\mathrm{AChE}$ binding affected some generic physical properties of $\operatorname{PrP}$ amyloid fibrils. First, we used the fluorescence probe ANS to study the presence of hydrophobic clusters on the PrP fibrillar surface (Figure 4b). ANS binding to PrP fibrils resulted in higher fluorescence yield and a blue shift in the fluorescence spectrum, as expected for PrP fibril structures, compared to the weak

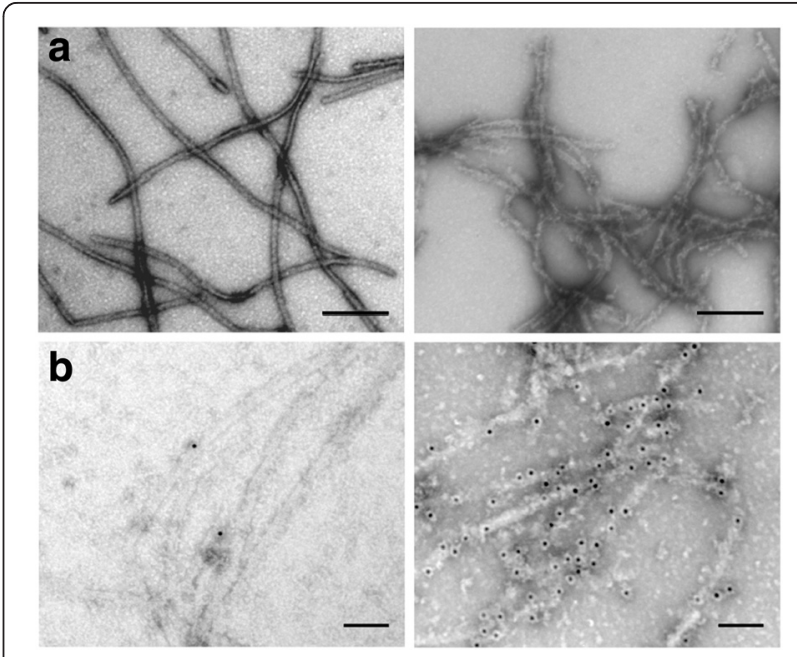

Figure 3 Macrostructure of the AChE-PrP fibril morphotype. Negative-stained transmission electron micrographs of PrP fibrils formed in the absence (left panels) or presence (right panels) of AChE, after direct deposition onto a grid (a), or following incubation with an anti-AChE antibody and a secondary antibody conjugated to 10-nm gold nanoparticles (b). The molar ratio used was 0.5:1 (AChE:PrP). All scale bars are $100 \mathrm{~nm}$. 
a

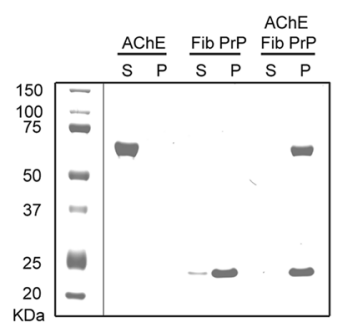

d

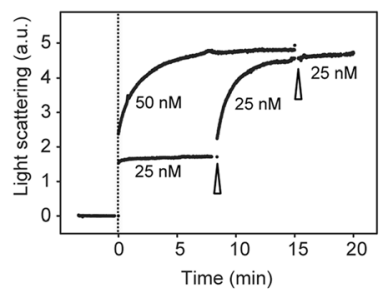

b

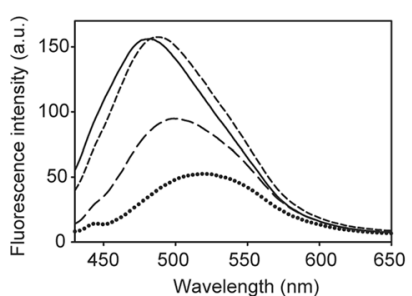

e

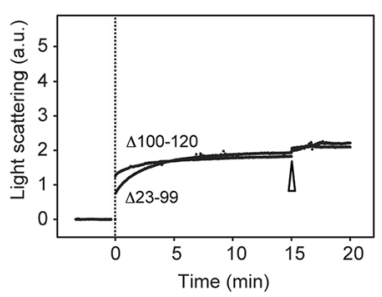

C

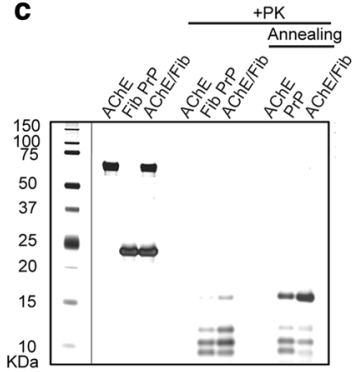

$\mathbf{f}$

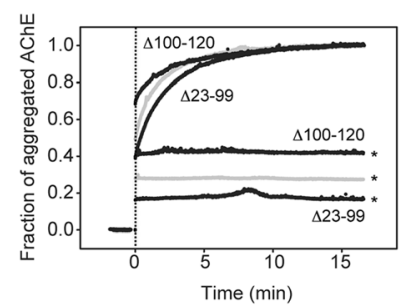

Figure 4 AChE associates with amyloid fibrils via the PrP N-terminus and affect their physical-chemical characteristics. This association is inhibited by Hup8TH. a Co-aggregation of AChE with preformed PrP fibrils (Fib PrP) was followed by Coomassie blue staining after SDS-PAGE of $10 \mu \mathrm{M}$ Fib PrP mixed with $5 \mu \mathrm{M}$ AChE at $37^{\circ} \mathrm{C}$ for 30 min. b AChE increases ANS binding to preformed PrP fibrils. ANS fluorescence emission spectra of monomeric PrP protein (dotted line), untreated PrP fibrils (long dashed line), fibrils after AChE association (short dashed line) and AChE alone (solid line). Samples correspond to either supernatant or pelleted fractions obtained after centrifugation. Final protein concentrations: $10 \mu \mathrm{M}$ PrP, $5 \mu \mathrm{M}$ AChE. Incubation conditions: $37^{\circ} \mathrm{C}$ for $30 \mathrm{~min}$. c Altered digestion profile of the PK-resistant core of PrP fibrils after AChE binding. Silver staining following electrophoretic separation of PrP fibrils $(10.5 \mu \mathrm{M})$ incubated or not with AChE $(0.5 \mu \mathrm{M})$, before and after PK digestion (+PK). The annealing procedure involves brief heating of the sample at $80^{\circ} \mathrm{C}$ in the presence of detergent. $\mathbf{d}$ Kinetics of AChE-PrP fibril

co-assembly. Light scattering intensity was used to follow the increase in the average molecular weight during successive additions (indicated by an arrowhead) of $25 \mathrm{nM}$ AChE to $50 \mathrm{nM}$ preformed PrP fibrils. The vertical dotted line indicates when AChE was first added (time zero). Saturation occurs at equimolar concentrations. The profile obtained after a single addition of $50 \mathrm{nM}$ AChE to the fibrillar sample is also shown to emphasize the equivalent total amplitude change. e AChE interacts with PrP fibrils obtained from two N-terminal truncated PrP variants ( $\triangle 100-120$ and $\triangle 23-99)$ and reaches saturation at half the molar ratio (0.5:1, AChE:PrP), compared to full-length PrP fibrils. Two successive additions (indicated by an arrowhead) of $25 \mathrm{nM}$ AChE to the two truncated PrP fibrils (50 nM) were performed. $\mathbf{f}$ Hup8TH decreases the binding of AChE to PrP fibrils. AChE was pre-incubated at room temperature with Hup8TH at a molar ratio of 1:20 (AChE:Hup8TH) for 30 min. Then, 50 nM PrP fibrils obtained from full-length PrP were incubated with $50 \mathrm{nM}$ pre-treated (grey line with asterisk) or non-inhibited AChE (grey line without asterisks). The same experiment was performed using the two truncated PrP fibrils and with $25 \mathrm{nM}$ (according to the saturation values observed in e) of pre-inhibited (black lines with asterisks) or not (black lines without asterisks) AChE. Data were normalized between 0 and 1 to easily compare the effects of the AChEi on the fraction of aggregated AChE. Experiments were performed in $20 \mathrm{mM}$ Mes buffer (pH 6.0) at $37^{\circ} \mathrm{C}$; a.u., arbitrary units. Molecular weights (in kilodaltons) are indicated to the left of the blots.

fluorescence yield observed after ANS binding to soluble PrP [51]. Upon ANS binding to the complex formed between pre-formed PrP fibrils and AChE, the fluorescence spectrum was further enhanced and blue-shifted, showing the presence of additional structured hydrophobic domains. This spectrum was therefore consistent with the observed AChE coating of PrP fibrils.

In addition, we carried out PK digestion to assess alterations in the PrP PK-resistant core after AChE binding (Figure 4c). Compared to PrP amyloid fibrils, the low molecular weight bands in AChE:PrP fibril complexes were more intense (for a densitometric analysis of the corresponding bands see Additional file 3), with a substantial increase of the PK-resistant core and a stronger $\sim 16-\mathrm{kDa}$ PK-resistant band. These differences were further substantiated after annealing, a procedure specific for amyloid $\operatorname{PrP}$ structures that induces conformational rearrangements within PrP fibrils [43]. In the AChE:PrP fibril complex, the characteristic $16-\mathrm{kDa}$ band was much intensified, when compared to PrP fibrils alone. These results are consistent with the gain of structural and conformational integrity of PrP fibrils after AChE interaction.

To better understand the mechanism of AChE binding to the PrP amyloid form, we then performed SLS kinetic measurements by successively adding $25 \mathrm{~nm}$ AChE to $50 \mathrm{nM}$ of pre-formed PrP fibrils (Figure 4d). An increase in light scattering that reflected the raise in the average molecular weight of the sample was observed, suggesting the formation of a stable complex between AChE and fibrillar PrP. Moreover, the signal was saturated when the molar ratio of 1:1 (PrP:AChE) was reached. As expected, a single addition of an equimolar concentration of $\mathrm{AChE}$ (50 $\mathrm{nM})$ had the same effect. 
To determine the PrP region involved in the AChE-PrP fibril interaction, we used SLS to investigate the interaction between $\mathrm{AChE}$ and two fibrillar samples obtained from two N-terminally truncated PrP variants lacking either residues $23-99$ or 100-120, the two mutually exclusive sub-sites for the AChE-PrP interaction that we previously identified using monomeric PrP. AChE bound to both truncated fibrils. Nevertheless, and in contrast to full-length PrP fibrils that contain both sub-sites, the kinetic profiles reached a plateau at a molar ratio of 0.5:1 (AChE:PrP) (Figure 4e). A subsequent addition of AChE did not further increase the average molecular weight of each fibrillar sample.

\section{Hup8TH reduces AChE-binding to PrP fibrils}

To examine whether AChE binding to PrP fibrils depends, as for monomeric PrP, on the same AChE hotspot that can be targeted by Hup8TH, we studied by SLS the effect of Hup8TH on AChE interaction with amyloid fibrils obtained from full length, $\Delta 23-99$ and $\Delta 100-120$ PrPs. To this aim, we pre-incubated $\mathrm{AChE}$ with its inhibitor a molar ratio of 1:20 (AChE: Hup8TH) at room temperature for $30 \mathrm{~min}$. Then, we added the mixture to each of the three PrP fibrillar forms. Hup8TH strongly inhibited AChE binding to all PrP fibrils (Figure 4f, traces with asterisks). Moreover, AChE binding reduction was dependent on the PrP fibrillar form used and thus on the presence/absence of the two Nterminal sub-sites that are essential for this heterologous interaction. The resulting fraction of protein complexes estimated for full-length $\operatorname{PrP}$ fibrils in the presence of Hup8TH $(\sim 30 \%)$ corresponded approximately to the mean of the values obtained for fibrils formed from the truncated PrP variants.

\section{The interaction of AChE with PrP fibrils inhibits AChE enzymatic activity and enhances PrP fibril cytotoxicity}

We next determined whether PrP fibrils have any effect on the enzyme activity by assessing AChE enzymatic activity in the absence or presence of $25 \mu \mathrm{M}$ monomeric or fibrillar PrP (3500 molar excess) (Figure 5a, left panel). Whereas no change was observed using monomeric PrP, AChE was completely inhibited after $30 \mathrm{~min}$ of incubation in the presence of fibrils. This inhibition was linearly proportional to the concentration of PrP fibrils (Figure 5a, right panel).

Finally, to investigate whether AChE interaction with PrP increases PrP toxicity we compared the cytotoxicity of soluble monomeric PrP, AChE and of the mix obtained after 30 min incubation, as well as of PrP amyloid fibrils and preformed amyloid fibrils associated with AChE by Hoechst nuclear staining of primary neuronal cells (Figure 5b). Monomeric PrP caused only a minor toxic effect, whereas the complex with AChE was three times more toxic, with a neuronal cell death rate comparable to that of PrP fibrils.
The fibrillar morphotype arising from AChE association with PrP fibrils showed the highest cytotoxicity.

\section{Prion-infected $\mathrm{AChE}^{+/-}$mice display slightly but significantly increased survival time}

We then examined whether partial AChE gene knockdown in transgenic mice, which reportedly leads to a $25-35 \%$ decrease in AChE activity [52], could affect prion disease tempo in vivo. Following intracerebral inoculation of 139A prions, the mean survival time of $\mathrm{AChE}^{+/-}$mice $(160 \pm$ 1 days, $n=9$ ) was slightly but significantly longer than that of wild type mice $(151 \pm 3, \mathrm{n}=7)(\mathrm{p}=0.03$ Mann-Whitney $\mathrm{U}$ test). However, at the terminal stage of disease, there was no difference in the brain accumulation and regional distribution of $\mathrm{PrP}^{\mathrm{Sc}}$ in $\mathrm{AChE}^{+/-}$and wild type mice.

\section{Prion infection selectively alters AChE levels in vivo and in cell cultures}

We tested whether AChE levels were altered in vivo in response to prion infection. We injected brain homogenates infected or not (mock) with LA21K fast prions in transgenic tg338 mice that express ovine PrP (VRQ/VRQ PrP genotype). At the terminal stage of the disease, we measured the levels of AChE transcripts, protein and enzymatic activity in cerebral cortex-enriched homogenates (Figure 6a) and in the brain fractions containing the remaining structures (Figure $6 b)$ from each infected mouse $(n=5)$ and agematched mock-infected controls $(n=5)$.

RT-qPCR quantification showed that AChE mRNA levels were increased by two-fold in cortical-enriched extracts of infected mice compared to controls (Figure 6a, right panel). Conversely, the cholinergic ChAT mRNA levels were not significantly different (Additional file 4), suggesting that prion disease affects $\mathrm{AChE}$ in a specific manner. In addition, no difference in the splicing pattern of the $A C H E$ gene was observed in the two groups. As expected, AChE-T mRNA (95\%) was more abundant than AChE-R and AChE-H mRNAs (Additional file 4). ACHE gene up-regulation was accompanied by a comparable change in $\mathrm{AChE}$ protein expression in prion-infected brains compared to controls (Figure 6a). However, AChE activity was not increased compared to control mice, suggesting that prion infection causes $\mathrm{AChE}$ inhibition in these brain areas. Indeed, normalization of AChE activity values to AChE protein content, as estimated by western blotting, indicated that AChE catalytic activity was decreased by nearly $40 \%$ in the in cortical-enriched extracts of infected mice.

In the rest of the brain of infected mice, no increase in AChE mRNA levels was observed compared to controls (Figure $6 \mathrm{~b}$, right panel), and $\mathrm{AChE}$ protein and activity levels were reduced by $25 \%$ (Figure 6b). Therefore, the normalized AChE activity, calculated based on AChE 

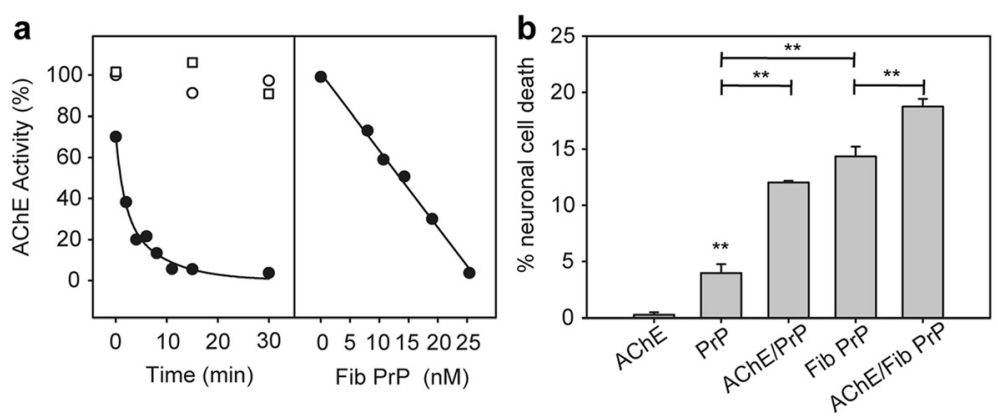

Figure 5 The interaction of AChE with PrP fibrils inhibits AChE enzymatic activity and enhances the cytotoxicity of both monomeric alpha-helix-rich and amyloid fibril PrP conformers in primary neurons. a PrP fibrils inhibit AChE enzymatic activity. Left panel: $7.3 \mathrm{nM}$ AChE was pre-incubated for different periods of time without (open circles) or with $25 \mu \mathrm{m}$ of monomeric (open squares) or fibrillar PrP (black circles) before initiation of the reaction with ACh. Right panel: Decrease in the observed AChE activity as a function of PrP fibril concentration. b Neurons were cultured for 2 days and then incubated with monomeric (PrP) or fibrillar (Fib) PrP isoforms (final concentration, $1 \mu \mathrm{M}$ ), $0.5 \mu \mathrm{M}$ AChE or the PrP-AChE mix. Neuronal cell death was quantified and expressed as the percentage relative to the value of control cells (vehicle). Each set of data is the mean value \pm S.D. (in percentage) of four experiments; five independent microscopic fields were counted for each experiment. ${ }^{* *} P<0.005$, one-way ANOVA. The Tukey test was used for post-hoc comparison after ANOVA.

protein content in these brain areas, was unchanged compared to control mice.

We then investigated whether the extra-cerebral AChE levels also were altered upon prion infection. We focused on the spleen, a secondary lymphoid organ in which prions can replicate and accumulate [53,54]. Despite noticeable inter-individual variability in the spleens of control mice, $\mathrm{AChE}$ protein level and enzymatic activity were very significantly lower (70\% and 96\% decrease, respectively) in spleen from infected mice compared to control (Figure 6c). Conversely, AChE mRNA levels were not changed compared to uninfected mice, indicating that $\mathrm{AChE}$ depletion during prion disease occurs via a post-transcriptional process and may be inherently linked to prion replication.

To investigate whether this phenomenon occurs in vitro in cultured cells, we examined AChE protein level and enzymatic activity in the neuroglial mouse cell line MOVS6 that is persistently infected with the $127 \mathrm{~S}$ scrapie strain, which phenotypically resembles LA21K fast prions [45]. Consistent with our findings in the spleen, both AChE protein and activity levels were reduced in infected cells, by $66 \%$ and $45 \%$, respectively, compared to control mockinfected cells (Figure 7).

\section{Discussion}

Here, we provide conclusive evidence that AChE can be functionally linked to PrP misfolding. This novel function of AChE, which is present in the biological environment where PrP replication may occur naturally, brings crucial knowledge on prion structural changes and their potential pathobiological implications. In this work, we addressed the relationships between the formation of $\mathrm{AChE} / \operatorname{PrP}$ hetero-assemblies and i) their cytotoxicity in primary neuronal cultures, as well as the extended survival of prion-infected $\mathrm{AChE}^{+/-}$mice; ii) the interference of dual-site binding AChE inhibitors with prion accumulation; and iii) the altered AChE homeostasis in both nervous and lymphoreticular systems of prion-infected mice and in chronically infected cell cultures.

\section{AChE confers new properties to PrP amyloid fibrils}

We show that AChE facilitates PrP aggregation and/or confers new structural properties to PrP amyloid fibrils. AChE incorporation into PrP amyloid fibrils substantially increases the PK-resistant core and specifically leads to a stronger $\sim 16-\mathrm{kDa}$ PK-resistant band, similar to that of naturally occurring $\operatorname{PrP}^{\mathrm{Sc}}$ and to infectious synthetic prions $[55,56]$. This supports the idea that AChE facilitates a conformational rearrangement in which the PrP region between residues $\sim 90$ and 140 adopts a PK-resistant conformation, which is thought to be critical for $\operatorname{PrP}$ conversion to a $\operatorname{PrP}^{\mathrm{Sc}}$-like molecule [43]. In addition, AChE assembly with PrP amyloid fibrils leads to enhanced hydrophobic exposure and significantly higher cytotoxicity in primary cultured neurons, compared to non-complexed PrP fibrils. Elevated neurotoxicity is also observed when $\mathrm{AChE}$ aggregates with the soluble PrP conformer. Thus, the longer survival observed in animals with lower AChE activity can be explained by a reduced amount of cytotoxic $\operatorname{PrP}$ morphotypes. The strongly reduced life expectancy and other abnormalities of $\mathrm{AChE}^{-/-}$mice [57] currently do not allow studying the consequences of complete depletion of AChE on prion pathogenesis. It remains to be investigated whether $\mathrm{AChE}$ is present in scrapieassociated fibrils. Nevertheless, it is unlikely that under harsh biochemical conditions, such as detergent extraction and proteinase $\mathrm{K}$ digestion used to extract scrapieassocaited fibrils [58], PrP will co-purify with potential binding partners that it complexes with inside the cell. 

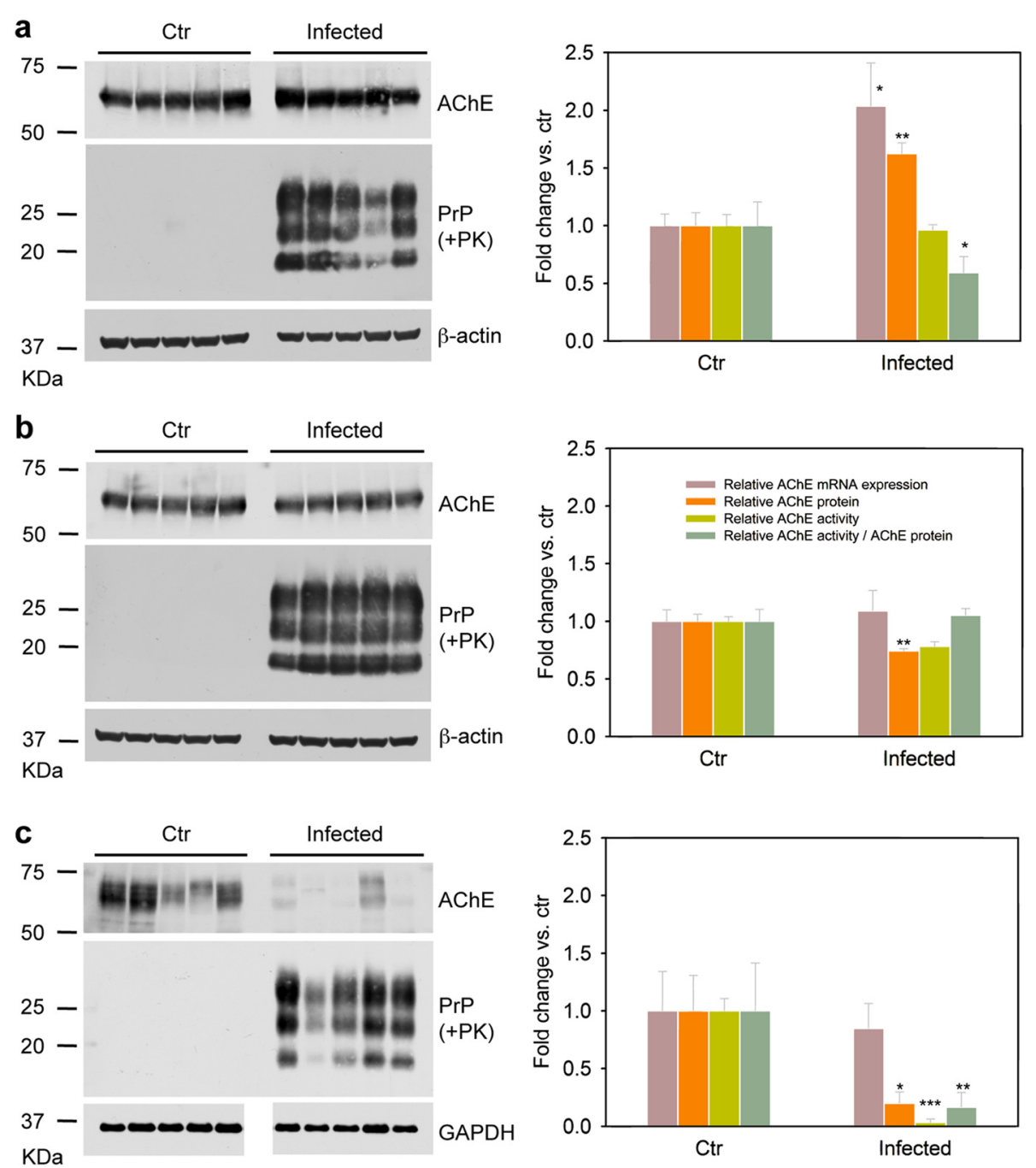

Figure 6 AChE levels are altered in the brain and spleen of prion-infected mice. Left panels: Western blot analysis of cerebral cortex-enriched homogenates (a), brain extracts containing the remaining structures (b), and spleen homogenates (c) prepared from tg338 mice expressing ovine PrP (VRQNRQ PrP genotype) and infected with LA21K fast prions or not (controls, Ctr). All inoculated mice $(n=5)$ developed prion disease, as indicated by the presence of $\mathrm{PrP}^{\mathrm{SC}}$, and showed altered AChE protein levels compared to age-matched, mock-infected controls $(n=5)$. $\beta$-actin or GAPDH levels are shown as loading control. Molecular weighs (in kilodaltons) are indicated on the left of the blots. Right panels: Vertical bar charts comparing the levels of AChE transcripts, protein and enzymatic activity in control and infected mice. Values are presented as fold change relative to control mice. Data are the mean \pm SEM obtained from the indicated number of mice. mRNA levels of total AChE transcripts were normalized to HPRT expression in the same cDNA preparations. Densitometric quantification of AChE protein was normalized to $\beta$-actin (brain) or GAPDH (spleen). ${ }^{*} P<0.05,{ }^{* *} P<0.005$, ${ }^{* * *} P<0.001$ compared to controls (one-way ANOVA).

\section{lonic interactions and a druggable aromatic-rich hotspot contribute to the AChE-PrP complex formation}

The AChE-PrP interaction might be explained by the fact that AChE (i.e., each catalytic subunit constituting the enzyme) displays a very large dipole moment that is oriented approximately along the axis of the active-site gorge (Additional file 5a). This particular arrangement, which has an excess of negative charge on the surface near the entrance of the AChE catalytic gorge, renders the protein particularly prone to experiencing promiscuous electrostatic interactions. Therefore, the presence of an extended disordered N-terminal region with two positively charged sub-sites (Additional file 5b) in both the alpha-helix rich PrP monomer and amyloid PrP fibrils, might favor interaction with AChE. This heterologous interaction may partially mask the charge-charge repulsion between neighboring homo-molecules, thereby considerably increasing the local concentration of the protein, and favoring the rapid assembly. The lack of interaction with the $\mathrm{N}$-terminal truncated PrP $\Delta 23-120$ variant further reinforces our hypothesis.

We also explain why dual-site binding AChE inhibitors are endowed with anti-prion activity. Our in vitro studies show that the specific tight interaction of Hup8TH 

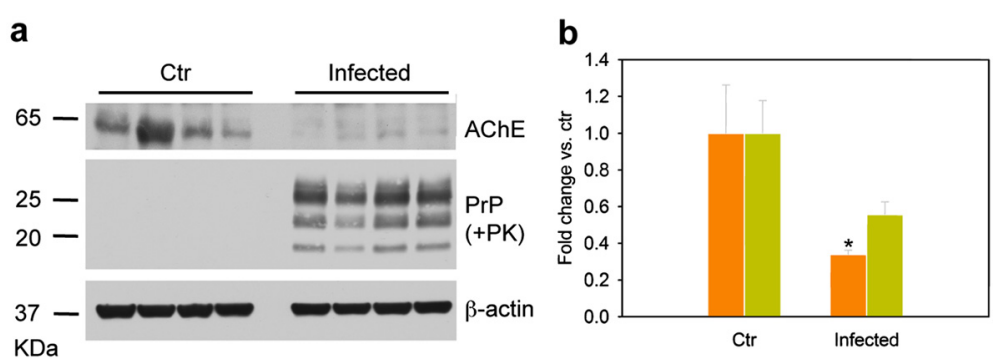

Figure 7 Decreased AChE levels in prion-infected MovS6 cells. a Western blot analysis of AChE levels in infected cells harboring PK-resistant $\operatorname{PrP}^{S}$. PrP ${ }^{S C}$ accumulation was determined with the anti-PrP antibody Sha31b; the anti- $\beta$-actin antibody was used to control protein loading. Ctr, mock-infected cells. Molecular weights (in kilodaltons) are indicated on the left of the blots. b Quantification of AChE protein (orange bars) and enzymatic activity (green bars) in mock-infected (Ctr) and prion-infected MovS6 cells. Values are presented as fold change relative to control cells. Data are the mean \pm SEM of four independent experiments for each condition. ${ }^{*} P<0.05$ one-way ANOVA.

(Additional file 5c), a dual-site binding AChEi, impairs AChE-PrP complex formation. Hup8TH, which is sandwiched between the PAS aromatic residues Trp286 and Tyr72 (in yellow in Additional file 5a) and the active-site gorge residues Tyr337 and Trp86 [59], occludes the AChE-PrP interface. These findings suggest that the precise assembly of the two oppositely charged proteins is critically dependent on such an aromatic-rich $\mathrm{AChE}$ hotspot. The proposed AChE-PrP binding mechanism is further supported by our results obtained using PrP fibrils lacking the 23-99 or 100-120 N-terminal PrP segments. The more positive charge distribution and rich aromatic character of the 23-99 region, compared to the 100-120 region, explain the different inhibition values observed with Hup8TH on AChE association to those fibrils. The anti-prion activity of Hup8TH in cell culture can therefore be ascribed to the displacement of the specific AChE-PrP interaction, further supporting $\mathrm{AChE}$ role in the formation of pathologically relevant PrP morphotypes.

\section{A Model of AChE-binding to PrP Amyloid Fibrils}

Although we do not yet have the atomic structures of full length PrP amyloid fibrils, several biochemical and biophysical studies suggest that the PrP fibril spine, which goes approximately from residue 160 to 225 , stacks inregister with parallel $\beta$-sheet strands spaced $4.8 \AA$ along the fibril axis [60-64]. The rest of the protein (i.e., the non-structured $\mathrm{N}$-terminus and the first $\alpha$-helix) must somehow accommodate at the periphery of the spine.

AChE crystal structure [65] and our estimation of its molecular weight in solution (Additional file 6) suggest the formation of a dimer with the identified interaction hotspot in each catalytic subunit facing the opposite sides of the complex (Additional file 5a).

On the basis of these previous structural studies and the present results, AChE binding to PrP fibrils can be schematized as follows (Figure 8). In fibrils, AChE binds to the 23-99 and 100-120 N-terminal PrP segments that should be solvent-exposed and accessible to extrinsic biological factors. However, $\mathrm{AChE}$ binding to these two regions of a monomeric PrP or fibrillar PrP protomer appears to be mutually exclusive and, thus, only one of the two sub-sites in the PrP N-terminus can be occupied by AChE without any steric hindrance. The 0.5:1 (AChE:PrP) stoichiometry found for fibrils composed of truncated PrP variants can be attributed to the particular structure of the dimeric $\mathrm{AChE}$ molecule, together with the precise arrangement of contiguous PrP molecules in a protofilament. These structural constraints could make adjacent N-terminal PrP regions sterically unavailable for interaction with AChE. Accordingly, only every second PrP protomer can be complexed with an AChE catalytic subunit. In the case of fulllength fibrils, $\mathrm{AChE}$ might circumvent the steric overlap to interact with contiguous $\operatorname{PrP}$ molecules by alternately interacting with the two $\mathrm{N}$-terminal $\mathrm{PrP}$ sites. This view is reinforced by the fact that half the number of AChE catalytic subunits are needed to completely saturate the binding sites of amyloid fibrils made from the two truncated PrP variants compared to those made from the full-length form. In addition, the intermediate association value of AChE with full-length fibrils in the presence of Hup8TH (30\%), compared to the values obtained for the truncated fibrils (40 and 20\%), is in agreement with the different AChE avidity for each PrP site and further supports the proposed mechanistic association model.

\section{Prion replication affects $\mathrm{AChE}$ homeostasis}

We found that AChE protein levels and ACHE transcripts are markedly increased in cerebral cortex-enriched homogenates from prion-infected tg 338 mice compared to mockinfected controls. Since, in this mouse model, both $\operatorname{PrP}^{\mathrm{C}}$ distribution in the brain and $\operatorname{PrP}$ expression ratios between brain and spleen are very similar to those found in conventional mice [66], our results indicate that AChE homeostasis is intrinsically altered upon prion replication and may be related to compensatory mechanisms leading to $A C H E$ gene expression up-regulation to counteract the decrease in $\mathrm{AChE}$ catalytic activity. These observations, together with 


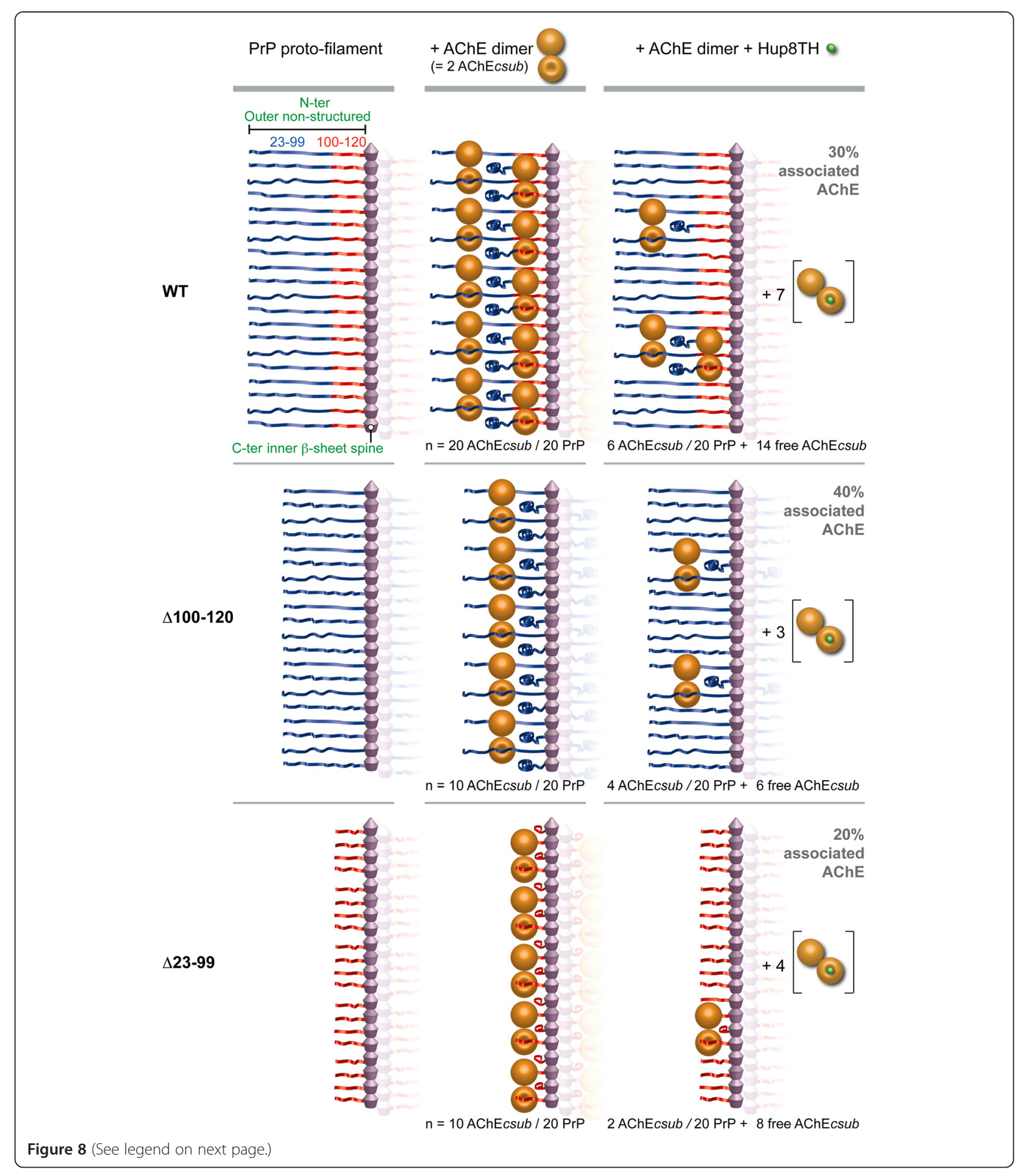


(See figure on previous page.)

Figure 8 Schematic representation of AChE binding to PrP amyloid fibrils. This model of AChE interaction within PrP fibrils was built using full-length PrP and its deletion variants, and is based on the data on Hup8TH inhibition of aggregation. We considered that each PrP proto-filament consisted of an inner spine and an outer non-structured region that includes approximately the N-terminus and the first a-helix of PrP. Due to the specific structural features of the dimeric AChE molecule and the supposed regular structure of the PrP fibril, each AChE catalytic subunit (AChEcsub) in the dimer may only interact with a non-contiguous PrP protomer in the protofilament. Thus, in the case of full-length PrP fibrils, AChEcsub may associate with adjacent PrP protomers by alternately interacting with the N-terminal sites within residues 23 and 99 (in blue) and residues 100 and 120 (in red). As AChE binding to both sites in the same PrP protomer appears to be mutually exclusive, an equimolar interaction between proteins is therefore obtained. Conversely, for fibrils formed from truncated N-terminal PrP variants ( $\Delta 100-120$ and $\Delta 23-99$ ), which are characterized by the loss of one of the AChE binding sites, only alternate PrP protomers may be complexed with AChE. N-terminal steric hindrance between adjacent PrP protomers thus leads to a 0.5:1 stoichiometry. The inhibition data using Hup8TH are in agreement with the proposed model and reveal that the two PrP N-terminal sites have similar binding mechanisms, but different avidities. The number ( $n$ ) of AChEcsub (associated and free) and PrP protomers is also shown. Further details are specified in the Discussion section.

the large decrease of both AChE protein levels and enzymatic activity in the spleen, where restorative mechanisms might be absent, indicate that $\mathrm{AChE}$ is not a mere bystander but might actively participate in prion disease pathogenesis. Furthermore, the finding that $\mathrm{AChE}$ homeostasis is altered also in the spleen of infected mice and in infected cell cultures, where $\operatorname{PrP}^{\mathrm{Sc}}$ accumulation appears rather benign [67], dismisses the possibility that the changes observed are the results of neurodegeneration or an artefact due to intracerebral inoculation, and supports the hypothesis that they arise in response to $\operatorname{PrP}^{\mathrm{Sc}}$ accumulation. Indeed, the presence of $\mathrm{AChE}$ in a variety of lymphoid and reticular cell types [68] and particularly in follicular dendritic cells of the germinal centers [69], the splenic cells in which prions might actively amplify, makes plausible a causative AChE-PrP interaction in prion pathogenesis. Nevertheless, the definitive functional link of $\mathrm{AChE}$ to this mechanism still remains to be determined. While the role of $\mathrm{AChE}$ in peripheral prion pathogenesis deserves further research, our findings are consistent with previous reports on reduced AChE activity in CSF samples of CJD patients and $\mathrm{AChE}$ altered glycosylation pattern in CJD CSF and brain tissue samples [32,33].

The specific mode of AChE interaction with PrP fibrils, as detailed before, may physically obstruct acetylcholine entry to the acylation site, and/or reduce its affinity by charge repulsion, thus explaining the inhibition of $\mathrm{AChE}$ enzymatic activity observed in the presence of fibrillar conformers, or in different prion-infected mice tissues. As mentioned above, the reduced AChE activity found in cortical-enriched extracts could stimulate AChE upregulation in these brain areas. Alternatively, in subcortical brain regions and spleen, as well as in cell cultures, AChE complexed with PrP could become more susceptible or exposed to proteolytic degradation. The lack of compensatory mechanisms will lead to a reduction of the AChE load. Our model is also congruent with the celland tissue-dependent differences in N-terminal trimming of $\mathrm{PrP}^{\mathrm{Sc}}$ [70]. Indeed, in both MovS cells and spleen tissue, $\mathrm{PrP}^{\mathrm{Sc}}$ accumulates predominantly as trimmed species, but still contains the 100-120 N-terminal $\operatorname{PrP}$ sub-site to which AChE can bind.

\section{Conclusions}

In summary, we report that $\mathrm{AChE}$ acts as an auxiliary molecule in PrP misfolding, leading to $\operatorname{PrP}$ morphotypes with potential relevance in prion diseases. Our finding that targeting a druggable site in AChE blocks the formation of these complexes is conceptually attractive and might be used for therapeutic strategies to target prion diseases and other protein misfolding disorders. Indeed, there is strong evidence for $\mathrm{AChE}$ involvement in $\mathrm{A} \beta$-induced neuronal dysfunction and $A \beta$ fibril formation $[18,19,21,22,20]$. In parallel, $\operatorname{PrP}$ also mediates $A \beta$ neurotoxicity [71]. The functional involvement of both $A C h E$ and $\operatorname{PrP}$ in $A D$, together with the AChE-PrP assemblies described here, reveals intriguing similarities between $\mathrm{AD}$ and prion diseases that could bring fundamental insights into their origins and progression. In this context, $\mathrm{AChE}$ could act as a common denominator in the pathogenesis of both diseases and its pharmacological targeting could thus provide broader neuroprotection.

\section{Additional files}

Additional file 1: Hup8TH does not interact with PrP. Thermal unfolding of PrP in the absence (solid line) or presence (dotted line) of Hup8TH, at equimolar concentrations, recorded by DSC.

Additional file 2: The macrostructure of the new AChE-induced PrP fibril morphotype is different from that of classical PrP fibrils. Negative-stained transmission electron micrographs of pre-formed PrP fibrils alone (left panel) or mixed with AChE (right panel). The molar ratio used was 0.5:1 (AChE:PrP). Scale bar $=100 \mathrm{~nm}$.

Additional file 3: Altered digestion profile of the PK-resistant core of PrP fibrils after AChE binding. a Silver staining following electrophoretic separation of PrP fibrils $(10.5 \mu \mathrm{M})$ incubated or not with AChE $(0.5 \mu \mathrm{M})$, before and after annealing. All fractions were PK treated. $b$ Densitometric analysis of the PK-resistant core of the corresponding samples. Data are mean \pm SEM values from four independent experiments. ${ }^{*} P<0.05,{ }^{* *} P<0.005$, vs. Fib PrP alone (one-way ANOVA). ns $=$ non significant.

Additional file 4: Cholinergic ChAT mRNA levels and the splicing pattern of the $A C H E$ gene are not significantly different in prion-infected mice compared to non-infected controls. a Vertical bar chart comparing the levels of ChAT transcripts in cerebral cortex-enriched homogenates from control and infected mice. Values are presented as fold change relative to control mice. Data are the mean \pm SEM for 5 mice/group. mRNA levels of total ChAT transcripts were normalized to HPRT transcript expression the same cDNA preparations. b Vertical bar chart comparing the levels of AChE T, H and R 
transcripts, relative to total AChE transcripts, in cerebral cortex-enriched homogenates from control and infected mice.

Additional file 5: Highly asymmetric surface charge distribution in AChE and PrP. Schematic representation of the three-dimensional structure and surface charges (red: negatively charged; blue: positively charged) of two different views of AChE (a) and PrP (b). The Coulomb potential was calculated by using the Poisson-Boltzmann equation as implemented in the Swiss-Pdb Viewer software and the crystallographic structures (1TQB for PrP, with a reconstituted N-terminal disordered segment; and 3LII for the dimeric recombinant human AChE). Each dimer consists of two AChE catalytic subunits (in light grey and in grey). The residues involved in the interaction with Hup8TH are in yellow. An excess of negative charge on the surface near the entrance of the AChE catalytic gorge and the positive character of the two N-terminal PrP segments (the 23-99 aa region is in blue and the 100-120 aa region in red) are shown. The figure was produced using Swiss-Pdb-Viewer. (c) Structure of the dual-binding site of the AChEi Hup8TH.

\section{Additional file 6: AChE molecular weight estimation by} multi-wavelength light scattering coupled to size-exclusion chromatography. AChE was loaded in a $60 \times 0.78 \mathrm{~cm}$ TSK4000SW column using an AKTA purifier100 FPLC device. The column exit was connected to a homemade multi-wavelength light scattering device with a scattering angle of $112^{\circ}$. The Rayleigh number leading to the estimation of the molecular weight was determined by using carbonic anhydrase as standard. The estimated molecular weight corresponds to the mean value obtained from three different wavelengths: $406 \mathrm{~nm}$ (violet), $450 \mathrm{~nm}$ (blue) and $532 \mathrm{~nm}$ (red).

\section{Abbreviations}

PrP: Prion protein; ACHE: Acetylcholinesterase; ACHEi: Acetylcholinesterase inhibitor; PrPC: Host cellular PrP conformer; PrP ${ }^{S C}$ : Misfolded pathological PrP conformer; AD: Alzheimer's disease; AB: Amyloid $\beta$; PAS: Peripheral anionic site; CSF: Cerebrospinal fluid; $\mathrm{CHO}$ cells: Chinese hamster ovary cells; PK: Proteinase K; ThT: Thioflavin T; ANS: 8-anilino-1-naphthalene sulfonate; BSA: Bovine serum albumin; SLS: Static light scattering; DSC: Differential Scanning Calorimetry; TEM: Transmission Electron Microscopy; AChEcsub: AChE catalytic subunit.

\section{Competing interests}

The authors declare that they have no competing interests.

\section{Authors' contributions}

Conceived and designed the experiments: JT HR. Performed the experiments: JT AV DM MT FN AC KG IA LH RL VB HR. Analyzed the data: JT AV DM MT FN AC KG IA LH RL VB HR. Wrote the paper: JT. All authors read and approved the final manuscript.

\section{Acknowledgments}

We are grateful to the staff of the Animalerie Rongeurs (INRA, Jouy-en-Josas, France) for excellent animal care. We also thank Prof. P. Taylor (Skaggs School of Pharmacy and Pharmaceutical Sciences, University of California, San Diego, USA) for the gift of the anti-AChE antibody. We thank Veronique Perrier (Inserm, Montpellier, France) for helpful discussion. Joan Torrent (research scientist at Inserm) is grateful to Inserm for institutional support. Alba Vilchez-Acosta thanks Erasmus Programme for a mobility grant.

\section{Author details}

${ }^{1}$ Institut National de la Recherche Agronomique, UR892, Virologie Immunologie Moléculaires, Jouy-en-Josas F-78350, France. ' 'Laboratori de Química Farmacèutica (Unitat Associada al CSIC), Facultat de Farmàcia, and Institut de Biomedicina (IBUB), Universitat de Barcelona, Barcelona E-08028, Spain. ${ }^{3}$ Département de Toxicologie, Institut de Recherche Biomédicale des Armées, Brétigny-sur-Orge F-91223, France. ${ }^{4}$ Institut National de la Recherche Agronomique, UMR866, Université Montpellier 1, Dynamique Musculaire et Métabolisme, Montpellier F-34060, France. ${ }^{5}$ Université Montpellier 2 Montpellier F-34095, France. ${ }^{6}$ Inserm, U710, Montpellier F-34095, France. ${ }^{7}$ EPHE, Paris F-75007, France.

Received: 18 December 2014 Accepted: 16 January 2015 Published online: 03 April 2015

\section{References}

1. Castilla J, Saa P, Hetz C, Soto C (2005) In vitro generation of infectious scrapie prions. Cell 121(2):195-206, doi:10.1016/j.cell.2005.02.011

2. Deleault NR, Harris BT, Rees JR, Supattapone S (2007) Formation of native prions from minimal components in vitro. Proc Natl Acad Sci U S A 104(23):9741-6, doi:10.1073/pnas.0702662104

3. Prusiner SB (1982) Novel proteinaceous infectious particles cause scrapie. Science 216(4542):136-44

4. Aguzzi A, Baumann F, Bremer J (2008) The prion's elusive reason for being. Annu Rev Neurosci 31:439-77, doi:10.1146/annurev.neuro.31.060407.125620

5. Lee KS, Linden R, Prado MA, Brentani RR, Martins VR (2003) Towards cellular receptors for prions. Rev Med Virol 13(6):399-408, doi:10.1002/rmv.408

6. Linden R, Martins VR, Prado MA, Cammarota M, Izquierdo I, Brentani RR (2008) Physiology of the prion protein. Physiol Rev 88(2):673-728, doi:10.1152/physrev.00007.2007

7. Schneider B, Pietri M, Pradines E, Loubet D, Launay JM, Kellermann $O$ et al (2011) Understanding the neurospecificity of Prion protein signaling. Front Biosci 16:169-86

8. Deleault NR, Walsh DJ, Piro JR, Wang F, Wang X, Ma J et al (2012) Cofactor molecules maintain infectious conformation and restrict strain properties in purified prions. Proc Natl Acad Sci U S A 109(28):E1938-46, doi:10.1073/ pnas.1206999109

9. Ma J (2012) The role of cofactors in prion propagation and infectivity. PLoS Pathog 8(4):e1002589, DOI: 10.1371/journal.ppat.1002589

10. Aguzzi A, Heikenwalder M, Polymenidou M (2007) Insights into prion strains and neurotoxicity. Nat Rev Mol Cell Biol 8(7):552-61, doi:10.1038/nrm2204

11. Eichner T, Radford SE (2011) A diversity of assembly mechanisms of a generic amyloid fold. Mol Cell 43(1):8-18, doi:10.1016/j.molcel.2011.05.012

12. Hicks D, John D, Makova NZ, Henderson Z, Nalivaeva NN, Turner AJ (2011) Membrane targeting, shedding and protein interactions of brain acetylcholinesterase. J Neurochem 116(5):742-6, doi:10.1111/j.14714159.2010.07032x

13. Xie HQ, Liang D, Leung KW, Chen VP, Zhu KY, Chan WK et al (2010) Targeting acetylcholinesterase to membrane rafts: a function mediated by the proline-rich membrane anchor (PRiMA) in neurons. J Biol Chem 285(15):11537-46, doi:10.1074/jbc.M109.038711

14. Layer PG (1995) Nonclassical roles of cholinesterases in the embryonic brain and possible links to Alzheimer disease. Alzheimer Dis Assoc Disord 9(Suppl 2):29-36

15. Silman I, Sussman JL (2005) Acetylcholinesterase: 'classical' and 'non-classical' functions and pharmacology. Curr Opin Pharmacol 5(3):293-302, doi:10.1016/j.coph.2005.01.014

16. Greenfield SA, Zimmermann M, Bond CE (2008) Non-hydrolytic functions of acetylcholinesterase. The significance of C-terminal peptides. FEBS J 275(4):604-11, doi:10.1111/j.1742-4658.2007.06235.x

17. Soreq H, Seidman S (2001) Acetylcholinesterase-new roles for an old actor. Nat Rev Neurosci 2(4):294-302, doi:10.1038/35067589

18. Dinamarca MC, Sagal JP, Quintanilla RA, Godoy JA, Arrazola MS, Inestrosa NC (2010) Amyloid-beta-Acetylcholinesterase complexes potentiate neurodegenerative changes induced by the Abeta peptide. Implications for the pathogenesis of Alzheimer's disease. Mol Neurodegener 5:4, doi:10.1186/1750-1326-5-4

19. Inestrosa NC, Dinamarca MC, Alvarez A (2008) Amyloid-cholinesterase interactions. Implications for Alzheimer's disease. FEBS J 275(4):625-32, doi:10.1111/j.1742-4658.2007.06238.x

20. Reyes AE, Chacon MA, Dinamarca MC, Cerpa W, Morgan C, Inestrosa NC (2004) Acetylcholinesterase-Abeta complexes are more toxic than Abeta fibrils in rat hippocampus: effect on rat beta-amyloid aggregation, laminin expression, reactive astrocytosis, and neuronal cell loss. Am J Pathol 164(6):2163-74

21. Rees T, Hammond PI, Soreq H, Younkin S, Brimijoin S (2003) Acetylcholinesterase promotes beta-amyloid plaques in cerebral cortex. Neurobiol Aging 24(6):777-87

22. Rees TM, Berson A, Sklan EH, Younkin L, Younkin S, Brimijoin S et al (2005) Memory deficits correlating with acetylcholinesterase splice shift and amyloid burden in doubly transgenic mice. Curr Alzheimer Res 2(3):291-300

23. De Ferrari GV Canales MA, Shin I, Weiner LM, Silman I, Inestrosa NC (2001) A structural motif of acetylcholinesterase that promotes amyloid beta-peptide fibril formation. Biochemistry 40(35):10447-57

24. Sussman JL, Harel M, Frolow F, Oefner C, Goldman A, Toker L et al (1991) Atomic structure of acetylcholinesterase from Torpedo californica: a prototypic acetylcholine-binding protein. Science 253(5022):872-9 
25. Taylor P, Lappi S (1975) Interaction of fluorescence probes with acetylcholinesterase. The site and specificity of propidium binding. Biochemistry 14(9):1989-97

26. Castro A, Martinez A (2006) Targeting beta-amyloid pathogenesis through acetylcholinesterase inhibitors. Curr Pharm Des 12(33):4377-87

27. Holzgrabe U, Kapkova P, Alptuzun V, Scheiber J, Kugelmann E (2007) Targeting acetylcholinesterase to treat neurodegeneration. Expert Opin Ther Targets 11(2):161-79, doi:10.1517/14728222.11.2.161

28. Munoz-Torrero D (2008) Acetylcholinesterase inhibitors as disease-modifying therapies for Alzheimer's disease. Curr Med Chem 15(24):2433-55

29. Rampa A, Belluti F, Gobbi S, Bisi A (2011) Hybrid-based multi-target ligands for the treatment of Alzheimer's disease. Curr Top Med Chem 11(22):2716-30

30. Pera M, Martinez-Otero A, Colombo L, Salmona M, Ruiz-Molina D, Badia A et al (2009) Acetylcholinesterase as an amyloid enhancing factor in PrP82-146 aggregation process. Mol Cell Neurosci 40(2):217-24, doi:0.1016/j. mcn.2008.10.008

31. Pera M, Roman S, Ratia M, Camps P, Munoz-Torrero D, Colombo L et al (2006) Acetylcholinesterase triggers the aggregation of PrP 106-126. Biochem Biophys Res Commun 346(1):89-94, doi:10.1016/j.bbrc.2006.04.187

32. Silveyra MX, Cuadrado-Corrales N, Marcos A, Barquero MS, Rabano A, Calero M et al (2006) Altered glycosylation of acetylcholinesterase in Creutzfeldt-Jakob disease. J Neurochem 96(1):97-104, doi:10.1111/j.1471-4159.2005.03514.x

33. Silveyra MX, Garcia-Ayllon MS, Calero M, Saez-Valero J (2006) Altered glycosylation of acetylcholinesterase in the Creutzfeldt-Jakob cerebrospinal fluid. J Mol Neurosci: MN 30(1-2):65-6, doi:10.1385/JMN:30:1:65

34. Rezaei H, Marc D, Choiset Y, Takahashi M, Hui Bon Hoa G, Haertle T et al (2000) High yield purification and physico-chemical properties of full-length recombinant allelic variants of sheep prion protein linked to scrapie susceptibility. Eur J Biochem/FEBS 267(10):2833-9

35. Carletti E, Li H, Li B, Ekstrom F, Nicolet Y, Loiodice M et al (2008) Aging of cholinesterases phosphylated by tabun proceeds through O-dealkylation. J Am Chem Soc 130(47):16011-20, doi:10.1021/ja804941z

36. Camps P, Contreras J, Font-Bardia M, Morral J, Munoz-Torrero D, Solans X (1998) Enantioselective synthesis of tacrine - huperzine A hybrids. Preparative chiral MPLC separation of their racemic mixtures and absolute configuration assignments by X-ray diffraction analysis. Tetrahedron Asymmetry 9(9):835-49

37. Camps P, Formosa X, Munoz-Torrero D, Petrignet J, Badia A, Clos MV (2005) Synthesis and pharmacological evaluation of huprine-tacrine heterodimers: subnanomolar dual binding site acetylcholinesterase inhibitors. J Med Chem 48(6):1701-4, doi:10.1021/jm0496741

38. Archer F, Bachelin C, Andreoletti O, Besnard N, Perrot G, Langevin C et al (2004) Cultured peripheral neuroglial cells are highly permissive to sheep prion infection. J Virol 78(1):482-90

39. Vilette $D$, Andreoletti $O$, Archer F, Madelaine MF, Vilotte $J$, Lehmann $S$ et al (2001) Ex vivo propagation of infectious sheep scrapie agent in heterologous epithelial cells expressing ovine prion protein. Proc Natl Acad Sci U S A 98(7):4055-9, doi:10.1073/pnas.061337998

40. Feraudet C, Morel N, Simon S, Volland H, Frobert Y, Creminon C et al (2005) Screening of 145 anti-PrP monoclonal antibodies for their capacity to inhibit PrPSC replication in infected cells. J Biol Chem 280(12):11247-58, doi:10.1074/ jbc.M407006200

41. Jennings LL, Malecki M, Komives EA, Taylor P (2003) Direct analysis of the kinetic profiles of organophosphate-acetylcholinesterase adducts by MALDITOF mass spectrometry. Biochemistry 42(37):11083-91, doi:10.1021/bi034756x

42. Breydo L, Makarava N, Baskakov IV (2008) Methods for conversion of prion protein into amyloid fibrils. Methods Mol Biol 459:105-15, doi:10.1007/9781-59745-234-2_8

43. Bocharova OV, Makarava N, Breydo L, Anderson M, Salnikov W, Baskakov IV (2006) Annealing prion protein amyloid fibrils at high temperature results in extension of a proteinase K-resistant core. J Biol Chem 281(4):2373-9, doi:10.1074/jbc.M510840200

44. El Moustaine D, Perrier V, Acquatella-Tran Van Ba I, Meersman F, Ostapchenko VG, Baskakov IV et al (2011) Amyloid features and neuronal toxicity of mature prion fibrils are highly sensitive to high pressure. J Biol Chem 286(15):13448-59, doi:10.1074/jbc.M110.192872

45. Tixador P, Herzog L, Reine F, Jaumain E, Chapuis J, Le Dur A et al (2010) The physical relationship between infectivity and prion protein aggregates is strain-dependent. PLoS Pathog 6(4):e1000859, doi:10.1371/journal.ppat.1000859

46. Beringue V, Andreoletti O, Le Dur A, Essalmani R, Vilotte JL, Lacroux C et al (2007) A bovine prion acquires an epidemic bovine spongiform encephalopathy strain-like phenotype on interspecies transmission.
J Neurosci: Offic J Soc Neurosci 27(26):6965-71, doi:10.1523/JNEUROSCI. 0693-07.2007

47. Oumata N, Nguyen PH, Beringue V, Soubigou F, Pang Y, Desban $N$ et al (2013) The toll-like receptor agonist imiquimod is active against prions. PLoS One 8(8):e72112, doi:10.1371/journal.pone.0072112

48. Tribouillard-Tanvier D, Beringue V, Desban N, Gug F, Bach S, Voisset C et al (2008) Antihypertensive drug guanabenz is active in vivo against both yeast and mammalian prions. PLoS One 3(4):e1981, doi:10.1371/journal.pone.0001981

49. Camps P, El Achab R, Morral J, Munoz-Torrero D, Badia A, Banos JE et al (2000) New tacrine-huperzine A hybrids (huprines): highly potent tightbinding acetylcholinesterase inhibitors of interest for the treatment of Alzheimer's disease. J Med Chem 43(24):4657-66

50. Rezaei H, Choiset Y, Eghiaian F, Treguer E, Mentre P, Debey P et al (2002) Amyloidogenic unfolding intermediates differentiate sheep prion protein variants. J Mol Biol 322(4):799-814

51. Baskakov IV, Legname G, Baldwin MA, Prusiner SB, Cohen FE (2002) Pathway complexity of prion protein assembly into amyloid. J Biol Chem 277 (24):21140-8, doi:10.1074/jbc.M111402200

52. Espallergues J, Galvan L, Sabatier F, Rana-Poussine V, Maurice T, Chatonnet A (2010) Behavioral phenotyping of heterozygous acetylcholinesterase knockout ( $\mathrm{AChE}+/-)$ mice showed no memory enhancement but hyposensitivity to amnesic drugs. Behav Brain Res 206(2):263-73, doi:10.1016/j.bbr.2009.09.024

53. Collinge J (2001) Prion diseases of humans and animals: their causes and molecular basis. Annu Rev Neurosci 24:519-50, doi:10.1146/annurev. neuro.24.1.519

54. Prusiner SB (1998) Prions. Proc Natl Acad Sci U S A 95(23):13363-83

55. Makarava N, Kovacs GG, Bocharova O, Savtchenko R, Alexeeva I, Budka H et al (2010) Recombinant prion protein induces a new transmissible prion disease in wild-type animals. Acta Neuropathol 119(2):177-87, doi:10.1007/s00401-0090633-x

56. Zhang Z, Zhang Y, Wang F, Wang X, Xu Y, Yang H, et al (2013) De novo generation of infectious prions with bacterially expressed recombinant prion protein. FASEB journal : official publication of the Federation of American Societies for Experimental Biology. doi:10.1096/fj.13-233965

57. Duysen EG, Li B, Xie W, Schopfer LM, Anderson RS, Broomfield CA et a (2001) Evidence for nonacetylcholinesterase targets of organophosphorus nerve agent: supersensitivity of acetylcholinesterase knockout mouse to VX lethality. J Pharmacol Exp Ther 299(2):528-35

58. Moore RA, Timmes A, Wilmarth PA, Priola SA (2010) Comparative profiling of highly enriched $22 \mathrm{~L}$ and Chandler mouse scrapie prion protein preparations. Proteomics 10(15):2858-69, doi:10.1002/pmic.201000104

59. Galdeano C, Viayna E, Sola I, Formosa X, Camps P, Badia A et al (2012) Huprine-tacrine heterodimers as anti-amyloidogenic compounds of potential interest against Alzheimer's and prion diseases. J Med Chem 55(2):661-9, doi:10.1021/jm200840c

60. Cobb NJ, Sonnichsen FD, McHaourab H, Surewicz WK (2007) Molecular architecture of human prion protein amyloid: a parallel, in-register betastructure. Proc Natl Acad Sci U S A 104(48):18946-51, doi:10.1073/ pnas.0706522104

61. Lu X, Wintrode PL, Surewicz WK (2007) Beta-sheet core of human prion protein amyloid fibrils as determined by hydrogen/deuterium exchange. Proc Natl Acad Sci U S A 104(5):1510-5, doi:10.1073/pnas.0608447104

62. Makarava N, Baskakov IV (2008) The same primary structure of the prion protein yields two distinct self-propagating states. J Biol Chem 283 (23):15988-96, doi:10.1074/jbc.M800562200

63. Ostapchenko VG, Sawaya MR, Makarava N, Savtchenko R, Nilsson KP, Eisenberg D et al (2010) Two amyloid States of the prion protein display significantly different folding patterns. J Mol Biol 400(4):908-21, doi:10.1016/j.jmb.2010.05.051

64. Tycko R, Savtchenko R, Ostapchenko VG, Makarava N, Baskakov IV (2010) The alpha-helical C-terminal domain of full-length recombinant PrP converts to an in-register parallel beta-sheet structure in PrP fibrils: evidence from solid state nuclear magnetic resonance. Biochemistry 49(44):9488-97, doi:10.1021/bi1013134

65. Dvir H, Silman I, Harel M, Rosenberry TL, Sussman JL (2010) Acetylcholinesterase: from 3D structure to function. Chem Biol Interact 187(1-3):10-22, doi:10.1016/j.cbi.2010.01.042

66. Beringue V, Herzog L, Jaumain E, Reine F, Sibille P, Le Dur A et al (2012) Facilitated cross-species transmission of prions in extraneural tissue. Science 335(6067):472-5, doi:10.1126/science.1215659 
67. McGovern G, Jeffrey M (2007) Scrapie-specific pathology of sheep lymphoid tissues. PLoS One 2(12):e1304, doi:10.1371/journal.pone.0001304

68. Bellinger DL, Lorton D, Hamill RW, Felten SY, Felten DL (1993)

Acetylcholinesterase staining and choline acetyltransferase activity in the young adult rat spleen: lack of evidence for cholinergic innervation. Brain Behav Immun 7(3):191-204, doi:10.1006/brbi.1993.1021

69. Lampert IA, Van Noorden S (1996) Acetyl cholinesterase is expressed in the follicular dendritic cells of germinal centres: differences between normal and neoplastic follicles. J Pathol 180(2):169-74, doi:10.1002/(SICI)1096-9896 (199610)180:2<169::AID-PATH621>3.0.CO;2-D

70. Dron M, Moudjou M, Chapuis J, Salamat MK, Bernard J, Cronier S et al (2010) Endogenous proteolytic cleavage of disease-associated prion protein to produce C2 fragments is strongly cell- and tissue-dependent. J Biol Chem 285(14):10252-64, doi:10.1074/jbc.M109.083857

71. Lauren J, Gimbel DA, Nygaard HB, Gilbert JW, Strittmatter SM (2009) Cellular prion protein mediates impairment of synaptic plasticity by amyloid-beta oligomers. Nature 457(7233):1128-32, doi:10.1038/nature07761

\section{Submit your next manuscript to BioMed Central and take full advantage of:}

- Convenient online submission

- Thorough peer review

- No space constraints or color figure charges

- Immediate publication on acceptance

- Inclusion in PubMed, CAS, Scopus and Google Scholar

- Research which is freely available for redistribution 